\title{
Teletrabajo en tiempos de COVID-19
}

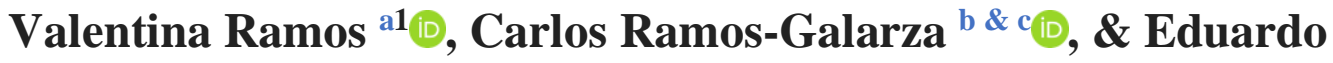 \\ Tejera $^{\mathrm{d}}{ }^{(1)}{ }^{2}$
}

\author{
Escuela Politécnica Nacional, Quito, Ecuador ${ }^{\text {a }}$; Pontificia Universidad \\ Católica del Ecuador, Quito, Ecuador ' ${ }^{\text {; }}$ Universidad Indoamérica, Quito, \\ Ecuador ${ }^{\mathrm{c}}$; Universidad de Las Américas, Quito, Ecuador ${ }^{\mathrm{d}}$.
}

\section{RESUMEN}

El COVID-19 como pandemia global tuvo consecuencias a nivel de la salud, pero también a nivel social pues como consecuencia de evitar su propagación los gobiernos tomaron medidas que afectaron al trabajo, adoptándose el teletrabajo como una alternativa para poder continuar con las actividades laborales desde el hogar. Este estudio analiza las características del teletrabajo y su impacto en la percepción de la productividad y el bienestar de las personas que se encuentran en aislamiento social debido al COVID-19. El estudio se realizó en Ecuador, en una muestra de 459 personas que respondieron un cuestionario en línea. Los resultados encontrados demuestran que hay aspectos que afectan la productividad, como trabajar largas horas, competencias personales, específicamente la auto-motivación y habilidades de organización, y la salud mental. Con esta investigación, se logra una mejor comprensión de la situación del teletrabajo en confinamiento debido a COVID-19, lo que permite que tanto las personas como las organizaciones desarrollen recursos para que el trabajo desde el hogar sea exitoso y las personas se sientan satisfechas mientras dura esta situación.

\section{Palabras Claves}

COVID-19; teletrabajo; satisfacción; productividad; salud mental; automotivación; recursos

\begin{abstract}
One of the impacts that COVID-19 has brought has been social isolation and teleworking. In this sense, telework presents different conditions to traditional ways of working from home, since in these conditions due to the COVI-19, there has been an increase in insecurity, fear and uncertainty. This study analyzes the characteristics of telework and its impact on productivity and well-being in people. The study was carried out in Ecuador, in a sample of 459 people who answered an online questionnaire. The results found demonstrate that there are aspects that affect productivity such as working long hours, personal skills, specifically self-motivation and organizational skills, and mental health. With this research, a better understanding of the situation of teleworking in confinement due to COVID-19 is achieved, allowing both individuals and organizations to develop resources so that work from home is successful and people feel satisfied while this situation lasts.
\end{abstract}

\section{Keywords}

COVID-19; telework; satisfaction; productivity; mental health; self-motivation; resources

\footnotetext{
1 Correspondence about this article should be addressed to Valentina Ramos: valentina.ramos@epn.edu.ec

2 Conflicts of Interest: The authors declare that the research was conducted in the absence of any commercial or financial relationships that could be construed as a potential conflict of interest.
} 


\section{TELEWORK IN TIMES OF COVID-19}

\section{Introducción}

La enfermedad por Coronavirus 2019 o COVID-19, fue determinada como pandemia mundial desde el mes de marzo de 2020 debido a su rápida expansión y su alto nivel infeccioso (Arce-Villalobos \& Rodriguez-Morales, 2020). En América Latina, a la fecha de este escrito, se han identificado más de 60 mil casos positivos de esta enfermedad, siendo los primeros países en número de contagios Brasil, Perú y Ecuador en ese orden (STATISTA, 2020). En el caso de Ecuador, hay que llamar la atención que es uno de los países más pequeños de América Latina, quedando en doceavo lugar en cuanto a su extensión, con una población estimada de más de 17 millones de habitantes de acuerdo con datos del Instituto Nacional de Estadística (INEC, 2020), quedando en séptimo lugar de países en América Latina en relación a número de habitantes. Ecuador tiene dos provincias principales: el Guayas, correspondiente a la región Costa, y Pichincha, correspondiente a la región Sierra y donde se encuentra la capital, Quito. Es decir, las características de Ecuador hacen que los estudios de enfermedad por Coronavirus y su impacto a nivel económicos y social sean especialmente necesarios, tanto por su condición territorial y poblacional, como por el lugar que ocupa a nivel de número de infestados en la región.

El primer caso de infección confirmada en Ecuador de enfermedad por el COVID19 tuvo lugar el 14 de febrero de 2020 (Dirección de Relaciones Públicas, 2020) y casi un mes más tarde, el 11 de marzo de 2020 se declara el estado de emergencia en el país y el 12 de marzo de 2020 se publican las directrices para el teletrabajo durante el período de emergencia sanitaria (Ministerio del Trabajo, 2019). Bajo este contexto, se consideró teletrabajo solamente como la alteración del espacio donde se trabaja, sin que esto afecte los derechos de los trabajadores (Ministerio del Trabajo, 2020). En consecuencia, de una cifra reportada en 2019 de 15 mil personas en modalidad de teletrabajo, la cifra aumentó a más de 235 mil personas una vez que apareció el acuerdo ministerial.

\section{El Teletrabajo o el Trabajo desde el Hogar}

El teletrabajo se ha definido dentro como una de las modalidades de las formas de trabajo flexibles. Estas formas también incluyen términos como trabajo remoto, trabajo móvil o e-trabajo (Crawford et al., 2011). En cualquier caso, autores como Crawford et al. (2011) han identificado como principal característica que estas modalidades tienen en 
común, la existencia de un contacto físico, cara a cara, inferior a las cuatro horas semanales con colegas o con jefes. De acuerdo con Beauregard et al. (2019), una de las razones principales por la que las personas optan por esta modalidad de trabajo ha sido la búsqueda de un equilibrio entre la vida laboral y la vida familiar. Tal es el caso, que estudios realizados por Beauregard et al. (2019) identificaron menores conflictos entre el trabajo y el hogar y, consecuentemente, una mayor sensación de bienestar mental.

Uno de los elementos principales del teletrabajo, es el uso de las tecnologías de la información y la comunicación para mantener el contacto con los supervisores y colegas, lo que se ha conocido como trabajo digital (Attaran et al., 2019). No necesariamente el teletrabajo implica trabajar desde el hogar, sino que hace referencia al lugar de elección del trabajador, fuera del contexto físico de las oficinas tradicionales (Beauregard et al., 2019; Neufeld \& Fang, 2005). Estudios realizados comparando las formas tradicionales de trabajo con el teletrabajo demostraron que las personas que realizan teletrabajo se esfuerzan más para ver cumplidos sus objetivos y no les importa alargar la jornada laboral con este fin, verificándose un mayor compromiso con su organización (Felstead \& Henseke, 2017). Siguiendo las comparaciones, entre los beneficios del teletrabajo se determinaron el aumento en el desempeño personal debido a la presencia de elementos como la flexibilidad de horarios, la autonomía para realizar las actividades y la ausencia de distractores, aunque se determinó que una de las causas negativas de este tipo de trabajo es la presencia de problemas relacionados con la salud mental (Beauregard et al., 2019; Crawford et al., 2011). De acuerdo con Crawford et al. (2011), adicional al aislamiento social que resulta típico de este tipo de actividad, los problemas que afectan la salud mental se deben al trabajo en largas jornadas, sensación de inseguridad en el trabajo, falta de control del tiempo y frustración por problemas de coordinación de actividades; elementos que se encontraron presente en actividades de teletrabajo. Asimismo, se identificó la dificultad de separar los espacios de trabajo y familiares cuando ambos coinciden y la falta de desconexión mental de los problemas de trabajo (Felstead \& Henseke, 2017).

Para la presente investigación, se tomó en cuenta el estudio por Neufeld y Fang (2005), donde proponen cuáles son los elementos críticos para la productividad tomando en cuenta al teletrabajo. Estos autores indican que hay tres elementos del teletrabajo que afectan a las personas y estos son los factores individuales como el género y el estatus social, factores sociales como las relaciones con los clientes, los supervisores, los colegas y la familia; y factores situacionales como los recursos y las distracciones. 
Adicionalmente, incorporamos el tema de competencias para el teletrabajo. Autores como Hamilton (2002) y Lewis (1994) argumentan que el éxito de las personas en el teletrabajo dependen de características como la automotivación, la organización, la autonomía y la extroversión, este último con una relación inversamente proporcional a la productividad en situación de teletrabajo.

\section{Condiciones del Teletrabajo en Situación de Crisis por Emergencia Sanitaria}

La modalidad de teletrabajo debido a una crisis sanitaria cobra otros aspectos adicionales a los anteriormente mencionados. Entre las consecuencias del impacto de la pandemia del COVID-19, los problemas de inseguridad relacionados con el trabajo se han agudizado, estimándose una reducción del empleo al 6,7\% (OIT, 2020b), afectando sobre todo los sectores donde no se puede adoptar una modalidad de trabajo alternativa como es el caso de los pequeños negocios. Adicionalmente se añade el miedo a enfermarse, por lo que los trabajos han adoptado medidas de protección a sus trabajadores (OIT, 2020a). En el caso específico de Ecuador, el estado de emergencia incluye la suspensión del derecho a la libertad de tránsito, reunión y asociación (PwC Ecuador, 2020); estableciéndose así un estado de aislamiento social por obligación, no por decisión personal, lo cual también se ha determinado como confinamiento. Al mismo tiempo, se suman otros elementos que afectan a la población mundial como la incertidumbre y el miedo.

Adicionalmente, a la condición de trabajo desde la casa se suman las responsabilidades con los hijos, los que también se encuentran confinados dentro de los hogares, por lo que la relación con la familia que parecería fuese uno de los principales beneficios del teletrabajo, en estas circunstancias son fuente de interrupciones y desconcentración. Estudios previos de condiciones de teletrabajo con hijos han demostrado que las personas se frustran más por la falta de fronteras entre la vida familiar y laboral (Kossek et al., 2009), donde las mujeres específicamente se sienten más perjudicadas pues al estar trabajando desde la casa con los hijos presentes, se refuerzan los roles tradicionales donde la madre tiene un papel fundamental en la crianza de los mismos (Hilbrecht et al., 2008). De este modo, las condiciones de teletrabajo en esta situación en particular cobra una connotación diferente y su estudio va a permitir entender qué mecanismos las personas necesitan para poder enfrentarse a este tipo de situaciones. Por esta razón, al modelo de Neufeld y Fang (2005) utilizado para evaluar productividad 
en teletrabajo, se incorporó el tema de bienestar mental de acuerdo con la propuesta de Beauregard y Basile (2019) y Crawford et al. (2011), que consideran este factor como uno de los elementos que afectan a las personas que están en condición de teletrabajo y que se adecua a las condiciones de aislamiento por COVID-19.

\section{Objetivo del Estudio}

Las condiciones de teletrabajo al momento son especiales, tal y como hemos argumentado anteriormente, debido al agravamiento de las condiciones de aislamiento social, el compartir los espacios laborales y familiares, la incertidumbre con relación al empleo y el miedo derivado de la pandemia. En el caso específico del Ecuador, el impacto de la pandemia se prevé que sea superior a muchos de los países de la región una vez que el número de infectados se incrementa en un país con una extensión pequeña y una cantidad de población bastante grande. Por estas razones, el objetivo de la presente investigación es determinar las características del teletrabajo en Ecuador, tomando en cuenta la situación de emergencia sanitaria dada por el COVID-19, y las relaciones entre estas características identificadas.

\section{Método}

\section{Muestra}

La muestra estuvo conformada por 459 personas de Ecuador, que al momento se encuentran en modalidad de teletrabajo. De acuerdo con Israel (1992), esta muestra es representativa de grandes poblaciones. A muestra fue heterogénea, siendo que las personas no fueron de la misma organización. El 70\% de la muestra indicó trabajar en el sector público, igualmente el $70 \%$ de la muestra hizo referencia a que formaba parte del sector de la educación. El 50\% de la muestra fue de género masculino y el 96\% indicó tener educación universitaria de pre y posgrado. El 92\% indicó que no vivía solo, el 50\% dijo que vivía con hijos menores y el $25 \%$ refirió que tiene un espacio privado para trabajar en la casa.

\section{Herramienta de recogida de información}

Para la recogida de información se elaboró una herramienta con base a las investigaciones de Beauregard et al. (2019), Crawford et al. (2011), Felstead y Henseke 
(2017), Hamilton (2002) y Neufeld y Fang (2005). El cuestionario diseñado estuvo compuesto por 72 preguntas, incluyendo una sección para los datos demográficos. Las preguntas se agruparon en las siguientes secciones: competencias para el éxito en el teletrabajo, características del trabajo, beneficios del teletrabajo, interacción social, recursos para trabajar desde la casa y salud mental.

\section{Procedimiento}

La encuesta se elaboró utilizando los formularios de Google y se distribuyó a través de las redes sociales y correos electrónicos, utilizando el formato de bola de nieve (Atkinson \& Flint, 2001). Al momento del llenado las personas podían escoger si deseaban participar o no en el estudio propuesto. El levantamiento de la información no comprometía la integridad y se garantizaba privacidad y anonimato de las respuestas. Como parte del mismo se contempló que aquellas personas que no estaban en teletrabajo no continuasen con el llenado de la herramienta. El cuestionario estuvo activo durante una semana. Para el análisis de la información no se establecieron factores, sino que las preguntas fueron analizadas como aspectos independientes del estudio. Las relaciones entre preguntas se realizaron utilizando el coeficiente de correlación de Pearson. Para la determinación del impacto sobre la productividad se hizo a través de regresiones lineares. El sistema estadístico utilizado para los cálculos fue el SPSS v.26.

\section{Resultados}

A continuación, presentaremos los resultados relacionados con los elementos asociados al teletrabajo que fueron considerados en el cuestionario. Adicionalmente se presentan las relaciones entre los mismos.

\section{Frecuencias de respuestas obtenidas para cada categoría}

En la Tabla 1 se muestran los resultados obtenidos teniendo en cuenta las frecuencias. Los mínimos y los máximos se colocan como referencia para interpretar las medias colocadas. El primero elemento considerado fue la existencia de Competencias en las personas relacionadas con el teletrabajo. 
Tabla 1.

Frecuencias de acuerdo con los aspectos de teletrabajo evaluados

\begin{tabular}{|c|c|c|c|c|}
\hline & Mínimo & Máximo & Media & $\begin{array}{c}\text { Desv. } \\
\text { Desviación }\end{array}$ \\
\hline \multicolumn{5}{|l|}{ Competencias } \\
\hline $\begin{array}{l}\text { Extroversión (buena comunicación y alta } \\
\text { sociabilidad) }\end{array}$ & 1 & 5 & 3,88 & 0,880 \\
\hline $\begin{array}{l}\text { Auto-motivación (capacidad de concentración y } \\
\text { realización de actividades sin depender de otros) }\end{array}$ & 1 & 5 & 4,15 & 0,830 \\
\hline $\begin{array}{l}\text { Autonomía para hacer las cosas (independencia de } \\
\text { los jefes y de otras personas para tomar decisiones } \\
\text { y realizar las actividades laborales) }\end{array}$ & 1 & 5 & 4,30 & 0,787 \\
\hline $\begin{array}{l}\text { Organización (alta estructuración de las tareas, } \\
\text { definiendo formas, modos y tiempos para las } \\
\text { mismas) }\end{array}$ & 1 & 5 & 4,03 & 0,872 \\
\hline \multicolumn{5}{|l|}{ Características del trabajo } \\
\hline Mi trabajo requiere un gran esfuerzo de mi parte & 1 & 5 & 4,19 & 0,918 \\
\hline $\begin{array}{l}\text { Tengo que trabajar largas jornadas para conseguir } \\
\text { hacer todo lo que tengo que hacer }\end{array}$ & 1 & 5 & 3,78 & 1,036 \\
\hline $\begin{array}{l}\text { Estoy dispuesto/a a trabajar más del tiempo } \\
\text { necesario para tener éxito }\end{array}$ & 1 & 5 & 4,07 & 0,976 \\
\hline Me siento a gusto con lo que hago & 1 & 5 & 4,31 & 0,850 \\
\hline Mi trabajo me hace sentirme optimista y entusiasta & 1 & 5 & 4,19 & 0,892 \\
\hline Estoy satisfecho con lo que hago & 1 & 5 & 4,30 & 0,831 \\
\hline $\begin{array}{l}\text { Después que termino de trabajar consigo } \\
\text { "desconectarme" de los problemas laborales }\end{array}$ & 1 & 5 & 3,58 & 1,204 \\
\hline Productividad & 1 & 3 & 1,92 & 0,763 \\
\hline \multicolumn{5}{|l|}{ Beneficios del teletrabajo } \\
\hline $\begin{array}{l}\text { Tengo lo que necesito para trabajar en un solo } \\
\text { lugar }\end{array}$ & 1 & 5 & 3,60 & 1,098 \\
\hline No tengo que estarme trasladando para trabajar & 1 & 5 & 4,08 & 0,999 \\
\hline No tengo interrupciones & 1 & 5 & 2,97 & 1,213 \\
\hline Me siento más relajado/a & 1 & 5 & 3,25 & 1,187 \\
\hline Es fácil equilibrar mi vida personal y laboral & 1 & 5 & 3,24 & 1,195 \\
\hline Siento menos estrés de trabajo & 1 & 5 & 3,17 & 1,250 \\
\hline $\begin{array}{l}\text { Mis pares y/o clientes se adaptan a este estilo de } \\
\text { trabajo }\end{array}$ & 1 & 5 & 3,28 & 1,067 \\
\hline Tengo flexibilidad en un horario para trabajar & 1 & 5 & 3,86 & 1,117 \\
\hline Este estilo se adapta a mi forma de trabajo & 1 & 5 & 3,33 & 1,153 \\
\hline \multicolumn{5}{|l|}{ Relaciones sociales } \\
\hline Clientes (incluye estudiantes) & 0 & 4 & 2,46 & 1,392 \\
\hline Colegas de trabajo & 0 & 4 & 3,22 & 1,016 \\
\hline Supervisores o jefes & 0 & 4 & 2,88 & 1,171 \\
\hline Familia (que no convive con Ud.) & 0 & 4 & 2,93 & 1,185 \\
\hline Amigos fuera del ámbito laboral & 0 & 4 & 2,38 & 1,227 \\
\hline $\begin{array}{l}\text { el teletrabajo ha causado problemas de } \\
\text { coordinación de actividades con. sus clientes } \\
\text { (incluye estudiantes) }\end{array}$ & 1 & 5 & 3,20 & 1,199 \\
\hline $\begin{array}{l}\text { el teletrabajo ha causado problemas de } \\
\text { coordinación de actividades con sus colegas de } \\
\text { trabajo }\end{array}$ & 1 & 5 & 2,98 & 1,112 \\
\hline
\end{tabular}


el teletrabajo ha causado problemas de

coordinación de actividades con sus supervisores

o jefes

el teletrabajo ha causado problemas de

no convive con $\mathrm{Ud}$.)

el teletrabajo ha causado problemas de

coordinación de actividades con sus amigos fuera

del ámbito laboral

Recursos para el teletrabajo

$¿$ Tiene un espacio específico para el teletrabajo

dentro de la casa?

Dispongo de toda la información para hacer mi

trabajo

Tengo autoridad suficiente para tomar decisiones

en el trabajo que hago

Mis actividades y responsabilidades están

claramente definidas

Mi jefe se preocupa por mi bienestar y que no me

falte nada

Tengo todos los equipos que necesito para poder

hacer mi trabajo

Recibo retroalimentación y tengo seguimiento de mi trabajo

Salud mental

Se ha sentido enfermo

Ha tenido dolores de cabeza

Ha sentido presión en la cabeza

Ha perdido el sueño por preocupaciones

Ha estado con problemas de conciliar el sueño

Se siente constantemente bajo estrés

Ha estado molesto y con mal temperamento

Ha estado nervioso todo el tiempo

Siente que las cosas le toman más tiempo para

hacerse

Se siente capaz de tomar buenas decisiones

Consigue disfrutar de las actividades diarias

Consigue mantenerse ocupado

Se siente una persona con menos valía

Siente que la vida no tiene sentido

Siente que no consigue hacer las cosas por su estado mental coordinación de actividades con su familia (que

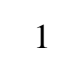

$$
5
$$

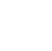

5

2,84

1,182

1

5

2,85

1,184

$\begin{array}{llll}1 & 2 & 1,25 & 0,435 \\ 1 & 5 & 3,85 & 1,098 \\ 1 & 5 & 3,96 & 1,010 \\ 1 & 5 & 4,20 & 0,882 \\ 1 & 5 & 3,27 & 1,238 \\ 1 & 5 & 3,59 & 1,168 \\ 1 & 5 & 3,56 & 1,146\end{array}$

1

\begin{tabular}{llll}
1 & 3 & 1,21 & 0,473 \\
1 & 3 & 1,34 & 0,582 \\
1 & 3 & 1,32 & 0,573 \\
1 & 3 & 1,49 & 0,688 \\
1 & 3 & 1,49 & 0,704 \\
1 & 3 & 1,44 & 0,688 \\
1 & 3 & 1,38 & 0,587 \\
1 & 3 & 1,34 & 0,581 \\
1 & 3 & 1,59 & 0,744 \\
1 & 3 & 1,49 & 0,694 \\
1 & 3 & 1,51 & 0,685 \\
1 & 3 & 1,79 & 0,783 \\
1 & 3 & 1,13 & 0,404 \\
1 & 3 & 1,14 & 0,432 \\
1 & 3 & 1,19 & 0,491 \\
& & & \\
\hline & & &
\end{tabular}

La Competencia menos frecuente fue la extroversión, mientras que la más frecuente, considerando las respuestas de las personas, fue la autonomía. Teniendo en cuenta las Características del Trabajo, se determinan altos niveles de satisfacción y de gusto por el mismo. Los elementos que aparecen como menos frecuentes es el tener que trabajar largas jornadas para conseguir lo que se quiere hacer, así como el poder desconectarse de los problemas del trabajo una vez que se termina dicha jornada laboral. Entre los Beneficios del Teletrabajo que, tradicionalmente, se han identificado y que 
fueron medidos, el único que tiene puntuaciones elevadas es el no tener que trasladarse a otros lugares para poder realizar las actividades laborales. El resto tuvieron puntuaciones bajas y el que más bajo tuvo fue la afirmación relacionada con ausencia de interrupciones al momento de trabajar. Es decir, hay una alta percepción de que no poder concentrarse en lo que se está haciendo al no tener privacidad.

Teniendo en cuenta las Relaciones Sociales, con quien más se perciben este tipo de interacciones es con colegas de trabajo, en menor escala se encuentran el resto de las personas como clientes, jefes y familiares y amigos. Los problemas más grandes de coordinación debido a la situación del teletrabajo se identifican con clientes o con estudiantes, los que entran dentro de la misma categoría. En relación con los Recursos para el teletrabajo, el elemento más positivo fue el hecho de que las actividades relacionadas con el trabajo se encuentran claramente definidas, por lo que las personas identifican que saben lo que tienen que hacer de acuerdo con sus funciones. Sin embargo, no existe un acuerdo en lo que se refiere al resto de Recursos. Las personas refieren que no siempre tienen todo lo que necesitan para trabajar dentro de la casa, hay problemas de acceso a la información y situaciones de descoordinación con los supervisores.

El último elemento considerado fueron los síntomas relacionados con la Salud Mental. Todos los elementos medidos tuvieron respuestas afirmativas en mayor o menor escala. Se puede destacar que los síntomas menos frecuentes fueron la sensación de falta de aprecio de uno mismo y de que la vida no tiene sentido. Entre los síntomas más frecuentes fueron la pérdida de sueño, el estrés, y la pérdida de la capacidad de tomar buenas decisiones. El elemento que más destacó en el contexto de salud mental fue la sensación de que las cosas toman más tiempo para su resolución.

\section{Productividad percibida en situación de teletrabajo en confinamiento}

De acuerdo con lo mostrado en la Tabla 1, podemos identificar que, en condiciones de teletrabajo dadas las condiciones actuales de confinamiento por COVID19, la percepción de productividad es que se ha mantenido o ha aumentado en algunos casos. Sin embargo, de todos los elementos medidos, aquellos que han influido en el aumento de la productividad han sido la auto-motivación y la organización en el caso de las competencias. Es decir, personas que consiguen definir sus propias actividades sin depender de los demás, y que adicionalmente mantiene niveles de estructuración y 


\section{RAMOS, RAMOS-GALARZA, \& TEJERA}

priorización de sus actividades, también tienen la percepción de que su productividad ha aumentado. Estos resultados se pueden ver en la Tabla 2.

Tabla 2

Valores de regresión entre componentes y percepción de la productividad en el teletrabajo

\begin{tabular}{|c|c|c|}
\hline & $\begin{array}{c}\text { Coeficiente } \\
\beta \\
\end{array}$ & $\begin{array}{c}\text { Significación } \\
p \\
\end{array}$ \\
\hline \multicolumn{3}{|l|}{ Competencias } \\
\hline $\begin{array}{l}\text { Extroversión (buena comunicación y alta } \\
\text { sociabilidad) }\end{array}$ & 0,034 & 0,433 \\
\hline $\begin{array}{l}\text { Auto-motivación (capacidad de concentración y } \\
\text { realización de actividades sin depender de otros) }\end{array}$ & 0,110 & 0,030 \\
\hline $\begin{array}{l}\text { Autonomía para hacer las cosas (independencia de } \\
\text { los jefes y de otras personas para tomar decisiones y } \\
\text { realizar las actividades laborales) }\end{array}$ & 0,020 & 0,706 \\
\hline $\begin{array}{l}\text { Organización (alta estructuración de las tareas, } \\
\text { definiendo formas, modos y tiempos para las } \\
\text { mismas) }\end{array}$ & 0,104 & 0,035 \\
\hline \multicolumn{3}{|l|}{ Características del trabajo } \\
\hline Mi trabajo requiere un gran esfuerzo de mi parte & $-0,051$ & 0,296 \\
\hline $\begin{array}{l}\text { Tengo que trabajar largas jornadas para conseguir } \\
\text { hacer todo lo que tengo que hacer }\end{array}$ & 0,157 & 0,003 \\
\hline $\begin{array}{l}\text { Estoy dispuesto/a a trabajar más del tiempo } \\
\text { necesario para tener éxito }\end{array}$ & $-0,109$ & 0,021 \\
\hline Me siento a gusto con lo que hago & $-0,119$ & 0,084 \\
\hline Mi trabajo me hace sentirme optimista y entusiasta & $-0,036$ & 0,604 \\
\hline Estoy satisfecho con lo que hago & 0,129 & 0,051 \\
\hline $\begin{array}{l}\text { Después que termino de trabajar consigo } \\
\text { "desconectarme" de los problemas laborales }\end{array}$ & 0,014 & 0,766 \\
\hline \multicolumn{3}{|l|}{ Beneficios del teletrabajo } \\
\hline $\begin{array}{l}\text { Tengo lo que necesito para trabajar en un solo } \\
\text { lugar }\end{array}$ & 0,144 & 0,019 \\
\hline No tengo que estarme trasladando para trabajar & 0,005 & 0,922 \\
\hline No tengo interrupciones & 0,150 & 0,010 \\
\hline Me siento más relajado/a & $-0,017$ & 0,810 \\
\hline Es fácil equilibrar mi vida personal y laboral & $-0,012$ & 0,866 \\
\hline Siento menos estrés de trabajo & $-0,054$ & 0,435 \\
\hline $\begin{array}{l}\text { Mis pares y/o clientes se adaptan a este estilo de } \\
\text { trabajo }\end{array}$ & 0,029 & 0,593 \\
\hline Tengo flexibilidad en un horario para trabajar & $-0,001$ & 0,991 \\
\hline Este estilo se adapta a mi forma de trabajo & 0,112 & 0,076 \\
\hline \multicolumn{3}{|l|}{ Relaciones sociales } \\
\hline Clientes (incluye estudiantes) & 0,027 & 0,546 \\
\hline Colegas de trabajo & 0,043 & 0,412 \\
\hline Supervisores o jefes & 0,024 & 0,638 \\
\hline Familia (que no convive con Ud.) & 0,014 & 0,772 \\
\hline Amigos fuera del ámbito laboral & $-0,142$ & 0,002 \\
\hline el teletrabajo ha causado problemas de & $-0,030$ & 0,567 \\
\hline
\end{tabular}


el teletrabajo ha causado problemas de coordinación de actividades con sus colegas de trabajo

el teletrabajo ha causado problemas de coordinación de actividades con sus supervisores o jefes

el teletrabajo ha causado problemas de coordinación de actividades con su familia (que no convive con Ud.)

el teletrabajo ha causado problemas de coordinación de actividades con sus amigos fuera del ámbito laboral

Recursos para el teletrabajo

¿Tiene un espacio específico para el teletrabajo dentro de la casa?

Dispongo de toda la información para hacer mi trabajo

Tengo autoridad suficiente para tomar decisiones en el trabajo que hago

Mis actividades y responsabilidades están claramente definidas

Mi jefe se preocupa por mi bienestar y que no me falte nada

Tengo todos los equipos que necesito para poder hacer mi trabajo

Recibo retroalimentación y tengo seguimiento de mi trabajo

Salud mental

Se ha sentido enfermo

Ha tenido dolores de cabeza

Ha sentido presión en la cabeza

Ha perdido el sueño por preocupaciones

Ha estado con problemas de conciliar el sueño

Se siente constantemente bajo estrés

Ha estado molesto y con mal temperamento

Ha estado nervioso todo el tiempo

Siente que las cosas le toman más tiempo para hacerse

Se siente capaz de tomar buenas decisiones

Consigue disfrutar de las actividades diarias

Consigue mantenerse ocupado

Se siente una persona con menos valía

Siente que la vida no tiene sentido

Siente que no consigue hacer las cosas por su estado mental

$\begin{array}{ll}-0,109 & 0,123 \\ 0,066 & 0,341\end{array}$

0,025

0,707

$-0,070$

$-0,072$

0,105

0,056

$-0,039$

0,482

0,023

0,681

0,024

0,645

$-0,127$

0,028

0,148

0,008

0,033

0,502

$-0,044$

0,475

$-0,072$

0,253

0,060

0,468

$-0,008$

0,917

0,064

0,303

0,073

0,181

0,116

0,027

$-0,226$

0,000

$0,060 \quad 0,226$

$0,065 \quad 0,217$

$-0,007 \quad 0,882$

$-0,049 \quad 0,340$

$-0,039 \quad 0,483$

$0,028 \quad 0,612$

Igualmente, de acuerdo con las regresiones mostradas en la Tabla 2, podemos verificar que los elementos relacionados con las características del trabajo que impactan la productividad son el extender la jornada laboral más allá que lo que tradicionalmente se considera dentro de la norma. Estando en la casa las personas sienten que tienen que trabajar largas jornadas para conseguir ser productivo en sus actividades. Entre los 
beneficios que tradicionalmente se otorgan al teletrabajo, aquellos cuya regresión ha sido estadísticamente significativa son la ausencia de interrupciones y la existencia de todas las condiciones de trabajo desde la casa. Personas que requieren de recursos como laboratorios o talleres no tienen la misma percepción, al no contar con los mismos en el espacio doméstico. Esto mismo se reconoce a nivel de recursos para trabajar: personas que identifican que cuentan con los insumos para su trabajo en la casa, así como que cuentan con retroalimentación por parte de sus jefes, tienen una percepción de un aumento de su productividad. A nivel social, la posibilidad de mantener una interacción social con los amigos ayuda a que la productividad aumente, confirmando la importancia de las relaciones sociales dentro de la vida de las personas. Por último, los aspectos de salud mental que impactan la productividad son la sensación de nerviosismo constante y la percepción de que las cosas toman más tiempo de lo necesario para realizarse.

\section{Relación entre competencias y otras características evaluadas del teletrabajo}

Se evaluaron cuatro competencias: la extroversión, la autonomía, la automotivación y la organización. Anteriormente mostramos que las competencias que más afectan la productividad fueron la automotivación y la organización, sin embargo, en la Tabla 3 podemos verificar que las cuatro competencias tienen relaciones significativas con otros componentes evaluados, relacionados con el teletrabajo.

Tabla 3

Correlaciones entre componentes y competencias para el éxito en el teletrabajo

\begin{tabular}{|c|c|c|c|c|}
\hline & Extroversión & $\begin{array}{l}\text { Auto- } \\
\text { motivación }\end{array}$ & $\begin{array}{l}\text { Autonomía } \\
\text { para hacer } \\
\text { las cosas }\end{array}$ & Organización \\
\hline \multicolumn{5}{|l|}{ Características del trabajo } \\
\hline $\begin{array}{l}\text { Mi trabajo requiere un gran esfuerzo } \\
\text { de mi parte }\end{array}$ & $-0,034$ &,$- 112 *$ & $-0,032$ & $-0,062$ \\
\hline $\begin{array}{l}\text { Tengo que trabajar largas jornadas } \\
\text { para conseguir hacer todo lo que } \\
\text { tengo que hacer }\end{array}$ & $-0,039$ & $-0,079$ & $-0,023$ &,$- 122 * *$ \\
\hline $\begin{array}{l}\text { Estoy dispuesto/a a trabajar más del } \\
\text { tiempo necesario para tener éxito }\end{array}$ & 0,058 & 0,021 & 0,032 & 0,002 \\
\hline Me siento a gusto con lo que hago &, $223 * *$ & ,208** &, $217 * *$ &, $189 * *$ \\
\hline $\begin{array}{l}\text { Mi trabajo me hace sentirme } \\
\text { optimista y entusiasta }\end{array}$ &, $157 * *$ & ,226** & $178 * *$ & ,197** \\
\hline Estoy satisfecho con lo que hago &, $163 * *$ & ,200** & ,208** &, $264 * *$ \\
\hline $\begin{array}{l}\text { Después que termino de trabajar } \\
\text { consigo "desconectarme" de los } \\
\text { problemas laborales }\end{array}$ & 0,072 &, $202 * *$ & $126 * *$ &, $219 * *$ \\
\hline \multicolumn{5}{|l|}{ Beneficios del teletrabajo } \\
\hline $\begin{array}{l}\text { Tengo lo que necesito para trabajar } \\
\text { en un solo lugar }\end{array}$ & $189 * *$ &, $180 * *$ & $186^{* *}$ &, $226 * *$ \\
\hline
\end{tabular}


No tengo que estarme trasladando para trabajar

No tengo interrupciones

Me siento más relajado/a

Es fácil equilibrar mi vida personal y laboral

Siento menos estrés de trabajo

Mis pares y/o clientes se adaptan a este estilo de trabajo

Tengo flexibilidad en un horario para trabajar

Este estilo se adapta a mi forma de trabajo

Relaciones sociales

Clientes (incluye estudiantes)

Colegas de trabajo

Supervisores o jefes

Familia (que no convive con Ud.)

Amigos fuera del ámbito laboral

el teletrabajo ha causado problemas de coordinación de actividades con. sus clientes (incluye estudiantes)

el teletrabajo ha causado problemas de coordinación de actividades con sus colegas de trabajo

el teletrabajo ha causado problemas de coordinación de actividades con sus supervisores o jefes

el teletrabajo ha causado problemas de coordinación de actividades con su familia (que no convive con Ud.) el teletrabajo ha causado problemas de coordinación de actividades con sus amigos fuera del ámbito laboral Recursos para el teletrabajo

¿Tiene un espacio específico para el teletrabajo dentro de la casa?

Dispongo de toda la información para hacer mi trabajo

Tengo autoridad suficiente para tomar decisiones en el trabajo que hago

Mis actividades y responsabilidades están claramente definidas

Mi jefe se preocupa por mi bienestar y que no me falte nada Tengo todos los equipos que necesito para poder hacer mi trabajo Recibo retroalimentación y tengo seguimiento de mi trabajo

Salud mental

Se ha sentido enfermo

Ha tenido dolores de cabeza

Ha sentido presión en la cabeza

Ha perdido el sueño por preocupaciones

\begin{tabular}{|c|c|c|c|}
\hline, $131 * *$ &, $140 * *$ &, $113^{*}$ &, $142 * *$ \\
\hline 0,073 &, $236 * *$ & 0,090 &, $203 * *$ \\
\hline 0,090 &, $156^{* *}$ &, $094 *$ &, $156 * *$ \\
\hline, $094 *$ &, $205 * *$ & 0,072 &, $273 * *$ \\
\hline 0,040 &, $108 *$ & 0,029 &, $149 * *$ \\
\hline 0,036 &, $129 * *$ &, $092 *$ &, $215 * *$ \\
\hline 0,014 & 0,077 &, $144 * *$ & 0,043 \\
\hline 0,088 &, $187 * *$ &, $170 * *$ &, $113^{*}$ \\
\hline, $143 * *$ & 0,032 & $-0,046$ & 0,007 \\
\hline, $100^{*}$ & 0,048 &,$- 095^{*}$ & $-0,018$ \\
\hline 0,039 & $-0,024$ &,$- 130 * *$ & 0,017 \\
\hline 0,006 & $-0,017$ & 0,017 & $-0,076$ \\
\hline, $103^{*}$ & $-0,022$ & 0,002 & 0,003 \\
\hline$-0,040$ & $-0,019$ & 0,017 &,$- 146^{* *}$ \\
\hline$-0,056$ &,$- 114^{*}$ &,$- 102 *$ &,$- 170 * *$ \\
\hline,$- 109 *$ &,$- 119 *$ &,$- 126 * *$ &,$- 194 * *$ \\
\hline,$- 103 *$ & $-0,077$ & $-0,066$ &,$- 149 * *$ \\
\hline$-0,061$ &,$- 095^{*}$ & $-0,030$ &,$- 095 *$ \\
\hline
\end{tabular}

$-0,069$

$-0,089$

$-, 168 * *$

$-, 177 * *$

,092*

,092*

, $170 * *$

, $149 * *$

0,070

,099*

, $332 * *$

, $128 * *$

0,064

,168**

, $165 * *$

,190**

0,009

0,060

0,011

0,071

,110*

, $132 * *$

, $176^{* *}$

, $169 * *$

0,073

, $126 * *$

0,063

, $154 * *$

$\begin{array}{cccc}-, 144 * * & -, 116 * & -, 122 * * & -, 165 * * \\ -, 167 * * & -, 194 * * & -, 198 * * & -, 160 * * \\ -, 153 * * & -, 191 * * & -, 203 * * & -, 161 * * \\ -0,083 & -, 143 * * & -, 206 * * & -, 129 * *\end{array}$


RAMOS, RAMOS-GALARZA, \& TEJERA

\begin{tabular}{|c|c|c|c|c|}
\hline $\begin{array}{l}\text { Ha estado con problemas de } \\
\text { conciliar el sueño }\end{array}$ & $-0,049$ &,$- 103 *$ &,$- 185 * *$ & $-0,080$ \\
\hline $\begin{array}{l}\text { Se siente constantemente bajo } \\
\text { estrés }\end{array}$ & $-0,086$ &,$- 133 * *$ &,$- 140 * *$ & $-0,086$ \\
\hline $\begin{array}{l}\text { Ha estado molesto y con mal } \\
\text { temperamento }\end{array}$ &,$- 124 * *$ &,$- 145^{* *}$ &,$- 162 * *$ &,$- 131 * *$ \\
\hline Ha estado nervioso todo el tiempo &,$- 160 * *$ &,$- 189 * *$ &,$- 214 * *$ &,$- 138 * *$ \\
\hline $\begin{array}{l}\text { Siente que las cosas le toman más } \\
\text { tiempo para hacerse }\end{array}$ &,$- 146 * *$ &,$- 248 * *$ &,$- 249 * *$ &,$- 238 * *$ \\
\hline $\begin{array}{l}\text { Se siente capaz de tomar buenas } \\
\text { decisiones }\end{array}$ & 0,053 & 0,060 & 0,082 &, $093 *$ \\
\hline $\begin{array}{l}\text { Consigue disfrutar de las } \\
\text { actividades diarias }\end{array}$ & 0,026 & 0,070 & 0,031 & 0,042 \\
\hline Consigue mantenerse ocupado & 0,055 & 0,060 & 0,014 & $-0,015$ \\
\hline $\begin{array}{l}\text { Se siente una persona con menos } \\
\text { valía }\end{array}$ & $-0,072$ &,$- 126 * *$ & $-0,055$ & $-0,056$ \\
\hline Siente que la vida no tiene sentido &,$- 095 *$ & $-0,070$ & $-0,073$ &,$- 104 *$ \\
\hline $\begin{array}{l}\text { Siente que no consigue hacer las } \\
\text { cosas por su estado mental }\end{array}$ &,$- 094 *$ &,$- 173 * *$ &,$- 134 * *$ &,$- 121 * *$ \\
\hline
\end{tabular}

En el caso de las características del trabajo, todas las competencias correlacionaron de forma estadísticamente significativa y positiva con la satisfacción, el optimismo y el gusto por lo que se hace. Sin embargo, la automotivación tuvo una correlación significativa y negativa con el esfuerzo, y la organización tuvo una correlación significativa y negativa con la necesidad de trabajar largas jornadas para cumplir con las actividades.

En el caso de los beneficios del teletrabajo, las cuatro competencias tuvieron correlaciones significativas y positivas con tener todas las condiciones de trabajo en un solo lugar, así como con no tener que trasladarse para poder hacer el trabajo que se requiere. Es decir, personas altamente competitivas consiguen aprovechar mejor estas dos condiciones. Por otra parte, fueron la automotivación y la organización las competencias que correlacionaron con el resto de los recursos para trabajar, sintiendo menos interrupciones, más equilibrio con la vida personal y menos estrés.

Desde el punto de vista de las relaciones sociales, las correlaciones encontradas fueron muy puntuales para algunas de las competencias. El elemento que hubo en común para las cuatro competencias evaluadas fue la existencia de menos problemas de coordinación con jefes, de forma estadísticamente significativa. La competencia que más permitió la coordinación de actividades dentro y fuera del ámbito laboral fue la organización. 
Las cuatro competencias evaluadas permitieron identificar, a partir de las correlaciones estadísticamente significativas, el aprovechamiento de recursos, especialmente lo relacionado con el acceso y uso de la información y la existencia de equipos para poder realizar las actividades desde la casa. Las tres competencias que adicionalmente tuvieron correlaciones significativas con la existencia de autoridad para tomar decisiones y claridad en la definición de responsabilidades fueron la autonomía, la automotivación y la organización. Ninguna de las competencias tuvo correlaciones estadísticamente significativas con el apoyo del jefe como uno de los recursos medidos para tener éxito en el teletrabajo.

En cuanto a la salud mental, las cuatro competencias permiten, en sentido general, tener una mejor vivencia de la situación de teletrabajo, disminuyendo síntomas como malestar, dolores de cabeza, nerviosismo y mal temperamento. Adicionalmente, las cuatro competencias favorecen una disminución de la sensación de que no se pueden realizar las actividades debido a problemas de salud mental.

Relación entre las características del trabajo, los beneficios del teletrabajo, las relaciones sociales, los recursos y la salud mental

De acuerdo con la Tabla 4, las dos características del trabajo que más afectan al teletrabajo en cuanto a los beneficios percibidos el mismo son la necesidad de trabajar largas jornadas y la percepción de un esfuerzo para poder hacer todas las actividades.

Tabla 4

Correlaciones entre componentes y características del trabajo durante el teletrabajo

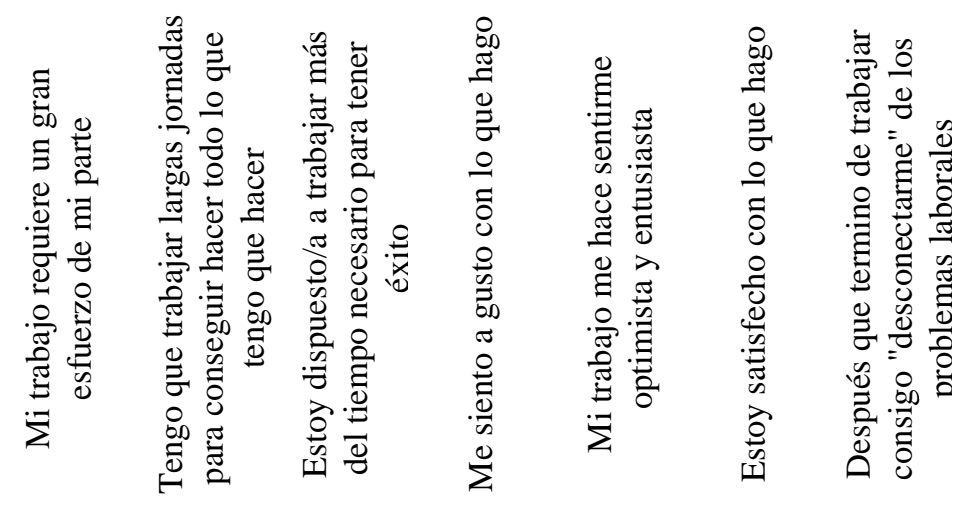

Beneficios del teletrabajo

Tengo lo que necesito para

0,023

0,022

$166 * *$

$314 * *$

$348 *$

$345 * *$

$221 * *$

No tengo que estarme

trasladando para trabajar

0,045

,098* 0,059

,216*

$, 173 * * \quad, 260 * * \quad, 100 *$

No tengo interrupciones

$-, 103$

$-, 121$

$168 * *$

$249 *$

,231*

,268** ,326**

Me siento más relajado/a

$-0,072$

$-, 118^{*}, 178 * *$

,332**

,214** ,246**

, $355^{* *}$ 
RAMOS, RAMOS-GALARZA, \& TEJERA

Es fácil equilibrar mi vida personal y laboral

Siento menos estrés de trabajo

Mis pares y/o clientes se adaptan a este estilo de trabajo

Tengo flexibilidad en un horario para trabajar

Este estilo se adapta a mi forma de trabajo

Relaciones sociales

Clientes (incluye

estudiantes)

Colegas de trabajo

Supervisores o jefes

Familia (que no convive con Ud.)

Amigos fuera del ámbito laboral

el teletrabajo ha causado problemas de coordinación de actividades con. sus clientes (incluye estudiantes)

el teletrabajo ha causado problemas de coordinación de actividades con sus colegas de trabajo el teletrabajo ha causado problemas de coordinación de actividades con sus supervisores o jefes el teletrabajo ha causado problemas de coordinación de actividades con su familia (que no convive con Ud.)

el teletrabajo ha causado problemas de coordinación de actividades con sus amigos fuera del ámbito laboral

Recursos para el teletrabajo

¿Tiene un espacio específico para el teletrabajo dentro de la casa?

Dispongo de toda la información para hacer mi trabajo

Tengo autoridad suficiente para tomar decisiones en el trabajo que hago

Mis actividades y

responsabilidades están claramente definidas

\begin{tabular}{|c|c|c|c|c|c|c|}
\hline,$- 123 * *$ &,$- 203 * *$ &, $167 * *$ &, $319 * *$ & ,299** &, $288 * *$ &, $379 * *$ \\
\hline,$- 100 *$ &,$- 175^{* *}$ &, $140 * *$ &, $326 * *$ &, $273 * *$ &, $246^{* *}$ & ,401** \\
\hline 0,048 & $-0,023$ &, $138 * *$ &, $290 * *$ &, $292 * *$ &, $274 * *$ &, $231 * *$ \\
\hline$-0,011$ & $-0,054$ &, $219 * *$ &, $384 * *$ & ,327** &, $316^{* * *}$ & ,209** \\
\hline$-0,004$ & $-0,002$ &, $204 * *$ &, $330 * *$ &, $281 * *$ &, $267 * *$ &, $246 * *$ \\
\hline ,098* &, $123 * *$ &, $146^{* *}$ &, $161 * *$ &, $153 * *$ &, $153 * *$ & $-0,054$ \\
\hline$-0,023$ & $-0,007$ & 0,087 & 0,036 & $-0,012$ & 0,023 & $-0,063$ \\
\hline 0,002 & $-0,065$ & 0,053 & $-0,040$ &,$- 094^{*}$ & $-0,020$ & $-0,018$ \\
\hline 0,031 & 0,008 & $-0,035$ & 0,034 & $-0,001$ & $-0,053$ & 0,022 \\
\hline$-0,038$ &,$- 105^{*}$ & 0,027 & 0,054 & 0,038 & 0,044 &, $111^{*}$ \\
\hline, $139 * *$ & ,099* & 0,010 & $-0,033$ & 0,028 & $-0,006$ & $-0,026$ \\
\hline, $126 * *$ &, $181 * *$ & $-0,019$ &,$- 124 * *$ & $-0,028$ & $-0,047$ & $-0,052$ \\
\hline 0,026 &, $143 * *$ & $-0,023$ &,$- 144 * *$ & $-0,047$ & $-0,060$ & $-0,050$ \\
\hline ,118* &, $140 * *$ & $-0,005$ & $-0,067$ & 0,021 & $-0,031$ & $-0,039$ \\
\hline
\end{tabular}

$\begin{array}{lllllll}, 116^{*} & , 126^{* *} & 0,002 & -0,045 & 0,029 & -0,033 & -0,044\end{array}$

\begin{tabular}{|c|c|c|c|c|c|c|}
\hline 0,007 & 0,039 & $-0,069$ &,$- 103 *$ &, $202^{-} * *$ &, $137^{-} *$ & $\overline{-}^{-}$ \\
\hline 0,034 & 0,009 &, $102 *$ &, $165^{* *}$ &, $171 * *$ &, $197 * *$ &, $174 * *$ \\
\hline 0,063 & 0,080 &, $178 * *$ &, $207 * *$ &, $278 * *$ &, $237 * *$ &, $186^{* *}$ \\
\hline, $100 *$ & $-0,035$ &, $169 * *$ &, $337 * *$ &, $316^{* *}$ &, $319 * *$ & 148 \\
\hline
\end{tabular}


Mi jefe se preocupa por mi bienestar y que no me falte nada

Tengo todos los equipos que necesito para poder hacer mi trabajo

Recibo retroalimentación y tengo seguimiento de mi trabajo

Salud mental

Se ha sentido enfermo
Ha tenido dolores de
cabeza
Ha sentido presión en la
cabeza
Ha perdido el sueño por
preocupaciones
Ha estado con problemas
de conciliar el sueño
Se siente constantemente
bajo estrés
Ha estado molesto y con
mal temperamento
Ha estado nervioso todo el
tiempo
Siente que las cosas le
toman más tiempo para
hacerse
Se siente capaz de tomar
buenas decisiones
Consigue disfrutar de las
actividades diarias
Consigue mantenerse
ocupado
Se siente una persona con
menos valía
Siente que la vida no tiene
sentido
Siente que no consigue
hacer las cosas por su
estado mental
eromato

\begin{tabular}{|c|c|c|c|c|c|c|}
\hline 0,054 &, $097 *$ & $-0,047$ &,$- 209 * *$ & $\begin{array}{c}- \\
, 152 * *\end{array}$ & $\begin{array}{c}- \\
, 205 * *\end{array}$ & $\begin{array}{c}- \\
, 188^{* *}\end{array}$ \\
\hline 0,084 &, $175^{* *}$ & $-0,074$ &,$- 257 * *$ & $-184 * *$ & $\begin{array}{c}- \\
, 207 * *\end{array}$ & $\begin{array}{c}- \\
, 148 * *\end{array}$ \\
\hline, $097 *$ &, $199 * *$ & $-0,061$ &,$- 240 * *$ & $\begin{array}{c}- \\
, 175^{* *}\end{array}$ & $\begin{array}{c}- \\
, 198^{* *}\end{array}$ & ${ }^{-}$ \\
\hline 0,071 &, $137 * *$ & $-0,050$ &,$- 198 * *$ & $\begin{array}{c}- \\
, 135 * *\end{array}$ & $\begin{array}{c}- \\
, 158 * *\end{array}$ & $241^{-}$ \\
\hline 0,039 &, $107 *$ & $-0,042$ &,$- 215 * *$ &,$- 114^{*}$ & $\begin{array}{c}- \\
, 125^{*} *\end{array}$ & $\begin{array}{c}- \\
, 189^{* *}\end{array}$ \\
\hline, $163 * *$ &, $273 * *$ &,$- 093 *$ &,$- 259 * *$ & $\begin{array}{c}- \\
, 211 * *\end{array}$ & $\begin{array}{c}- \\
, 173 * *\end{array}$ & - $318 * *$ \\
\hline, $124 * *$ &, $186 * *$ & $-0,055$ &,$- 259 * *$ & $\begin{array}{c}- \\
, 191 * *\end{array}$ & $\begin{array}{c}- \\
, 249 * *\end{array}$ & $231^{-}$ \\
\hline, $102 *$ & ,119* & $-0,008$ &,$- 215 * *$ & $\begin{array}{c}- \\
, 187 * *\end{array}$ & $\begin{array}{c}- \\
, 150 * *\end{array}$ & $\overline{-}^{-}$ \\
\hline, $152 * *$ &, $262 * *$ & $-0,064$ &,$- 274 * *$ & , $197 * *$ & , $213 * *$ & , $254 * *$ \\
\hline$-0,003$ & $-0,039$ & 0,032 & 0,036 & 0,058 & 0,054 & 0,057 \\
\hline$-0,055$ &,$- 094^{*}$ & 0,027 & 0,089 & 0,085 & 0,089 &, $092 *$ \\
\hline 0,013 &, $132 * *$ & 0,049 & $-0,050$ & 0,064 & 0,021 & $-0,068$ \\
\hline 0,039 &, $108 *$ & $-0,013$ & $-0,014$ & $-0,052$ & $-0,040$ &,$- 109 *$ \\
\hline 0,052 &, $121 * *$ & 0,029 & $-0,050$ &,$- 117 *$ & $-0,040$ & $-0,087$ \\
\hline 0,076 &, $170 * *$ & 0,081 & $-0,070$ &,$- 092 *$ & $-0,053$ & , $211^{* * *}$ \\
\hline
\end{tabular}

Nota: $\quad$ Los valores corresponden al coeficiente de correlación de Pearson. El *indica valores de $p<.05$ y **indica valores de $p>.001$

Estas características hacen que las personas sientan más estrés, aumenta la percepción de interrupciones y hace que sea difícil equilibrar la vida laboral y familiar. Sin embargo, ambas características correlacionan de manera significativa y positiva con las relaciones sociales, permitiendo una mejor coordinación con los actores que permiten que se desarrolle el trabajo, ya sea jefes y colegas, y entre actores que favorecen la vida social como amigos y familiares. Por su parte, en la misma Tabla 4 se refleja cómo el aumento de la satisfacción, el gusto por el trabajo y el entusiasmo por lo que se hace tienen una correlación estadísticamente significativa y positiva con aspectos de la salud mental. 
Tomando en cuenta los beneficios del teletrabajo, estos han afectado positivamente las posibilidades de tener una coordinación con personas dentro y fuera del contexto laboral. Es decir, las personas perciben que mientras más relajado se siente por el trabajo, mientras más flexible es la jornada laboral y mientras más concentrados los recursos para trabajar en un solo lugar, menos problemas para coordinar actividades con colegas, jefes, clientes e, incluso, con amigos y familiares. Estos resultados se muestran en la Tabla 5.

Tabla 5

Correlaciones entre componentes y beneficios del teletrabajo

\begin{tabular}{|c|c|c|c|c|c|c|c|c|c|}
\hline & 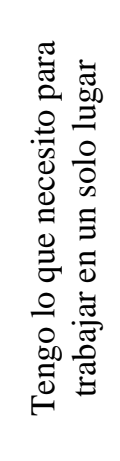 & 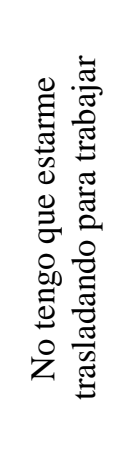 & 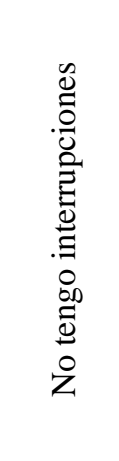 & 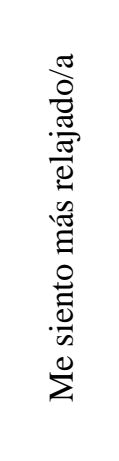 & 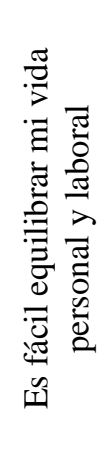 & 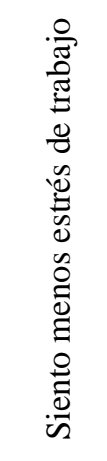 & 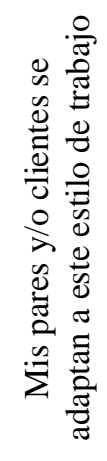 & 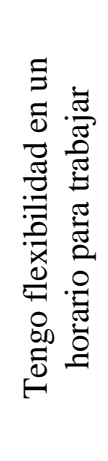 & 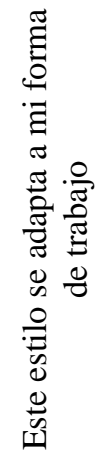 \\
\hline \multicolumn{10}{|l|}{ Relaciones sociales } \\
\hline $\begin{array}{l}\text { Clientes } \\
\text { (incluye } \\
\text { estudiantes) }\end{array}$ & 0,081 & 0,040 & 0,086 & 0,048 & 0,050 & 0,004 & $\begin{array}{c}124 * \\
*\end{array}$ & 0,012 &, $098 *$ \\
\hline $\begin{array}{l}\text { Colegas de } \\
\text { trabajo }\end{array}$ & 0,009 & $-0,012$ & 0,022 & 0,000 & 0,055 & $\begin{array}{c}- \\
0,015\end{array}$ &, $100^{*}$ & $\begin{array}{c}- \\
0,046\end{array}$ & 0,006 \\
\hline $\begin{array}{l}\text { Supervisores } \\
\text { o jefes }\end{array}$ & $-0,020$ & $-0,020$ & 0,047 & 0,007 & 0,059 & $\begin{array}{c}- \\
0,004\end{array}$ & 0,065 & $\begin{array}{c}- \\
0,088\end{array}$ & $\begin{array}{c}- \\
0,033\end{array}$ \\
\hline $\begin{array}{l}\text { Familia (que } \\
\text { no convive } \\
\text { con Ud.) }\end{array}$ & $-0,077$ & $-0,037$ & ${ }^{-}, 135 * *$ & $-0,050$ & 0,007 & 0,014 & - & 0,080 & 0,031 \\
\hline $\begin{array}{l}\text { Amigos fuera } \\
\text { del ámbito } \\
\text { laboral }\end{array}$ & 0,027 & 0,014 & 0,067 &, $175^{* *}$ & $\begin{array}{c}, 157 * \\
*\end{array}$ & $\begin{array}{c}138 * \\
*\end{array}$ & 0,045 & $\begin{array}{c}134 * \\
*\end{array}$ & $\begin{array}{c}127 * \\
*\end{array}$ \\
\hline el teletrabajo & - & - & - & - & - & - & - & - & - \\
\hline $\begin{array}{l}\text { ha causado } \\
\text { problemas de } \\
\text { coordinación } \\
\text { de actividades } \\
\text { con. sus } \\
\text { clientes } \\
\text { (incluye } \\
\text { estudiantes) }\end{array}$ &, $207 * *$ &, $159 * *$ &, $157 * *$ &, $178 * *$ & $\begin{array}{c}, 227 * \\
*\end{array}$ & $\begin{array}{c}, 149 * \\
*\end{array}$ & $\begin{array}{c}, 255^{*} \\
*\end{array}$ &, $115^{*}$ & $\begin{array}{c}, 245^{*} \\
*\end{array}$ \\
\hline el teletrabajo & - & - & - & - & - & - & - & - & - \\
\hline $\begin{array}{l}\text { ha causado } \\
\text { problemas de } \\
\text { coordinación } \\
\text { de actividades } \\
\text { con sus } \\
\text { colegas de } \\
\text { trabajo }\end{array}$ &, $178 * *$ &, $144 * *$ &, $136 * *$ &, $181 * *$ & $\begin{array}{c}, 209 * \\
*\end{array}$ & $\begin{array}{c}, 220 * \\
*\end{array}$ & $\begin{array}{c}, 248 * \\
*\end{array}$ & $\begin{array}{c}, 205^{*} \\
*\end{array}$ & $\begin{array}{c}, 278^{*} \\
*\end{array}$ \\
\hline
\end{tabular}


el teletrabajo ha causado problemas de coordinación de actividades con sus

supervisores o jefes

el teletrabajo ha causado problemas de coordinación de actividades con su familia (que no convive con Ud.)

el teletrabajo ha causado problemas de coordinación de actividades con sus amigos fuera del ámbito laboral

Recursos para el teletrabajo

Dispongo de toda la información para hacer mi trabajo

Tengo autoridad suficiente para tomar decisiones en el trabajo que hago

Mis

actividades y responsabilida des están claramente definidas Mi jefe se preocupa por mi bienestar y que no me falte nada Tengo todos los equipos que necesito para poder hacer mi trabajo

Recibo retroalimentaci ón y tengo

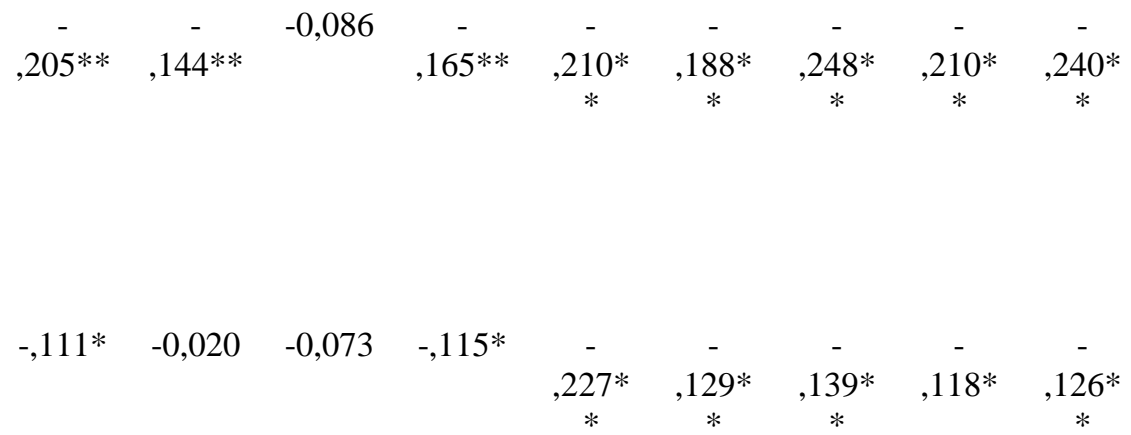




\section{RAMOS, RAMOS-GALARZA, \& TEJERA}

seguimiento de mi trabajo

Salud mental

\begin{tabular}{|c|c|c|c|c|c|c|c|c|c|}
\hline $\begin{array}{l}\text { Se ha sentido } \\
\text { enfermo }\end{array}$ & ,235** & ${ }^{-}$ & ${ }^{-}$ & , $275^{*} *$ & $\begin{array}{c}- \\
, 245^{*} \\
*\end{array}$ & $\begin{array}{c}- \\
, 282 * \\
*\end{array}$ & $\begin{array}{c}- \\
{ }^{-} \\
*\end{array}$ & $\begin{array}{c}- \\
167 * \\
*\end{array}$ & $\begin{array}{l}- \\
211 * \\
*\end{array}$ \\
\hline $\begin{array}{l}\text { Ha tenido } \\
\text { dolores de } \\
\text { cabeza }\end{array}$ & , $132 * *$ & , $128 * *$ & , $167 * *$ & , $281 * *$ & $\begin{array}{c}- \\
216^{*} \\
*\end{array}$ & $\begin{array}{c}- \\
, 244^{*} \\
*\end{array}$ & $\begin{array}{c}- \\
125^{*} \\
*\end{array}$ & $\begin{array}{l}- \\
198 * \\
*\end{array}$ & $\begin{array}{l}- \\
, 193 * \\
*\end{array}$ \\
\hline $\begin{array}{l}\text { Ha sentido } \\
\text { presión en la } \\
\text { cabeza }\end{array}$ & $-133 * *$ & ${ }^{-}$ & , $249 * *$ & , $352 * *$ & $\begin{array}{c}- \\
, 280 * \\
*\end{array}$ & $\begin{array}{c}- \\
\text {,307* } \\
*\end{array}$ & $\begin{array}{c}- \\
\text {, } 168 * \\
*\end{array}$ & $\begin{array}{c}- \\
213 * \\
*\end{array}$ & $\begin{array}{l}- \\
216^{*} \\
*\end{array}$ \\
\hline $\begin{array}{l}\text { Ha perdido el } \\
\text { sueño por } \\
\text { preocupacione } \\
\text { S }\end{array}$ & $-176 * *$ &,$- 107 *$ & , $215^{* *}$ & ${ }^{-}$ & $\begin{array}{c}- \\
\text {,320* } \\
*\end{array}$ & $\begin{array}{c}- \\
332 * \\
*\end{array}$ & $\begin{array}{c}- \\
{ }^{-143} \\
\end{array}$ & $\begin{array}{c}- \\
, 200 * \\
*\end{array}$ & $\begin{array}{c}- \\
, 258 * \\
*\end{array}$ \\
\hline $\begin{array}{l}\text { Ha estado con } \\
\text { problemas de } \\
\text { conciliar el } \\
\text { sueño }\end{array}$ & - $181 * *$ &,$- 092 *$ & , $174 * *$ & ,234** & $\begin{array}{c}- \\
, 259 * \\
*\end{array}$ & $\begin{array}{c}- \\
, 288 * \\
*\end{array}$ & $\begin{array}{c}- \\
134 * \\
*\end{array}$ & $\begin{array}{c}- \\
196 * \\
*\end{array}$ & $\begin{array}{l}- \\
239 * \\
*\end{array}$ \\
\hline $\begin{array}{l}\text { Se siente } \\
\text { constantement } \\
\text { e bajo estrés }\end{array}$ & ,230** & $-0,088$ & , $313^{*} *$ & , $413^{*} *$ & $\begin{array}{c}- \\
, 398 * \\
*\end{array}$ & $\begin{array}{c}- \\
, 459 * \\
*\end{array}$ & $\begin{array}{c}- \\
\text {, } \\
*\end{array}$ & $\begin{array}{c}- \\
\text {,309* } \\
*\end{array}$ & $\begin{array}{l}- \\
, 316^{*} \\
*\end{array}$ \\
\hline $\begin{array}{l}\text { Ha estado } \\
\text { molesto y con } \\
\text { mal } \\
\text { temperamento }\end{array}$ & , $231 * *$ & , $128 * *$ & , $339 * *$ & , $358 * *$ & $\begin{array}{c}- \\
367 * \\
*\end{array}$ & $\begin{array}{c}- \\
381 * \\
*\end{array}$ & $\begin{array}{c}- \\
178 * \\
*\end{array}$ & $\begin{array}{c}- \\
219 * \\
*\end{array}$ & $\begin{array}{l}- \\
299 * \\
*\end{array}$ \\
\hline $\begin{array}{l}\text { Ha estado } \\
\text { nervioso todo } \\
\text { el tiempo }\end{array}$ & , $125 * *$ &,$- 093 *$ & - $183 * *$ & , $236 * *$ & $\begin{array}{c}- \\
, 231 * \\
*\end{array}$ & $\begin{array}{c}- \\
, 282 * \\
*\end{array}$ & , $119 *$ & $\begin{array}{l}- \\
156^{*} \\
*\end{array}$ & $\begin{array}{l}- \\
, 172 * \\
*\end{array}$ \\
\hline $\begin{array}{l}\text { Siente que las } \\
\text { cosas le toman } \\
\text { más tiempo } \\
\text { para hacerse }\end{array}$ & , $234 * *$ & $-0,080$ & , $344 *$ & , $358 * *$ & $\begin{array}{l}- \\
408 * \\
*\end{array}$ & $\begin{array}{c}- \\
, 383 * \\
*\end{array}$ & $\begin{array}{c}- \\
229 * \\
*\end{array}$ & $\begin{array}{l}- \\
196 * \\
*\end{array}$ & $\begin{array}{l}- \\
, 308 * \\
*\end{array}$ \\
\hline $\begin{array}{l}\text { Se siente } \\
\text { capaz de tomar } \\
\text { buenas } \\
\text { decisiones }\end{array}$ &, $133 * *$ & 0,080 & $-0,006$ &, $111^{*}$ & 0,073 & 0,049 & $\begin{array}{c}137 * \\
*\end{array}$ & 0,071 & 0,065 \\
\hline $\begin{array}{l}\text { Consigue } \\
\text { disfrutar de las } \\
\text { actividades } \\
\text { diarias }\end{array}$ &, $149 * *$ &, $168 * *$ & 0,053 &, $186 * *$ & $\begin{array}{c}, 161 * \\
*\end{array}$ & $\begin{array}{c}, 193 * \\
*\end{array}$ & $\begin{array}{c}, 134 * \\
*\end{array}$ & $\begin{array}{c}, 185 * \\
*\end{array}$ & $\begin{array}{c}173^{*} \\
*\end{array}$ \\
\hline $\begin{array}{l}\text { Consigue } \\
\text { mantenerse } \\
\text { ocupado }\end{array}$ & 0,034 & 0,053 &,$- 114^{*}$ & $-0,080$ & , $108 *$ & - & 0,025 & 0,001 & 0,012 \\
\hline $\begin{array}{l}\text { Se siente una } \\
\text { persona con } \\
\text { menos valía }\end{array}$ & $-0,007$ & 0,000 & $-0,086$ & $\overline{-}^{-}, 125^{* *}$ & , $098 *$ & $\begin{array}{c}- \\
0,053\end{array}$ & $\begin{array}{c}- \\
0,027\end{array}$ & $\begin{array}{c}- \\
0,065\end{array}$ & $\begin{array}{c}- \\
0,061\end{array}$ \\
\hline $\begin{array}{l}\text { Siente que la } \\
\text { vida no tiene } \\
\text { sentido }\end{array}$ & $-0,087$ & $-0,046$ &,$- 093 *$ & , $131 * *$ & , $110^{-}$ & $\begin{array}{c}- \\
0,086\end{array}$ & - & $\stackrel{-}{0,060}$ & ,093* \\
\hline $\begin{array}{l}\text { Siente que no } \\
\text { consigue hacer } \\
\text { las cosas por } \\
\text { su estado } \\
\text { mental }\end{array}$ & $-0,077$ & $-0,050$ &,$- 105^{*}$ & , $121 * *$ & , $112 *$ & , $102 *$ & - & $\begin{array}{c}- \\
0,047\end{array}$ & $-\overline{-}$ \\
\hline
\end{tabular}

Nota: $\quad$ Los valores corresponden al coeficiente de correlación de Pearson. El *indica valores de $p<.05$ y **indica valores de $p>.001$ 
En esta Tabla 5, se puede verificar cómo los beneficios asociados al teletrabajo tienen una correlación estadísticamente significativa y negativa con la existencia de síntomas como el malestar, los problemas de sueño, el nerviosismo y el estrés.

Teniendo en cuenta las relaciones sociales, en la Tabla 6 se pueden verificar las correlaciones estadísticamente significativas que tienen los problemas de coordinación de actividades sociales, tanto laborales como familiares, con la presencia de síntomas negativos para la salud mental.

Tabla 6

Correlaciones entre componentes y relaciones sociales durante el teletrabajo
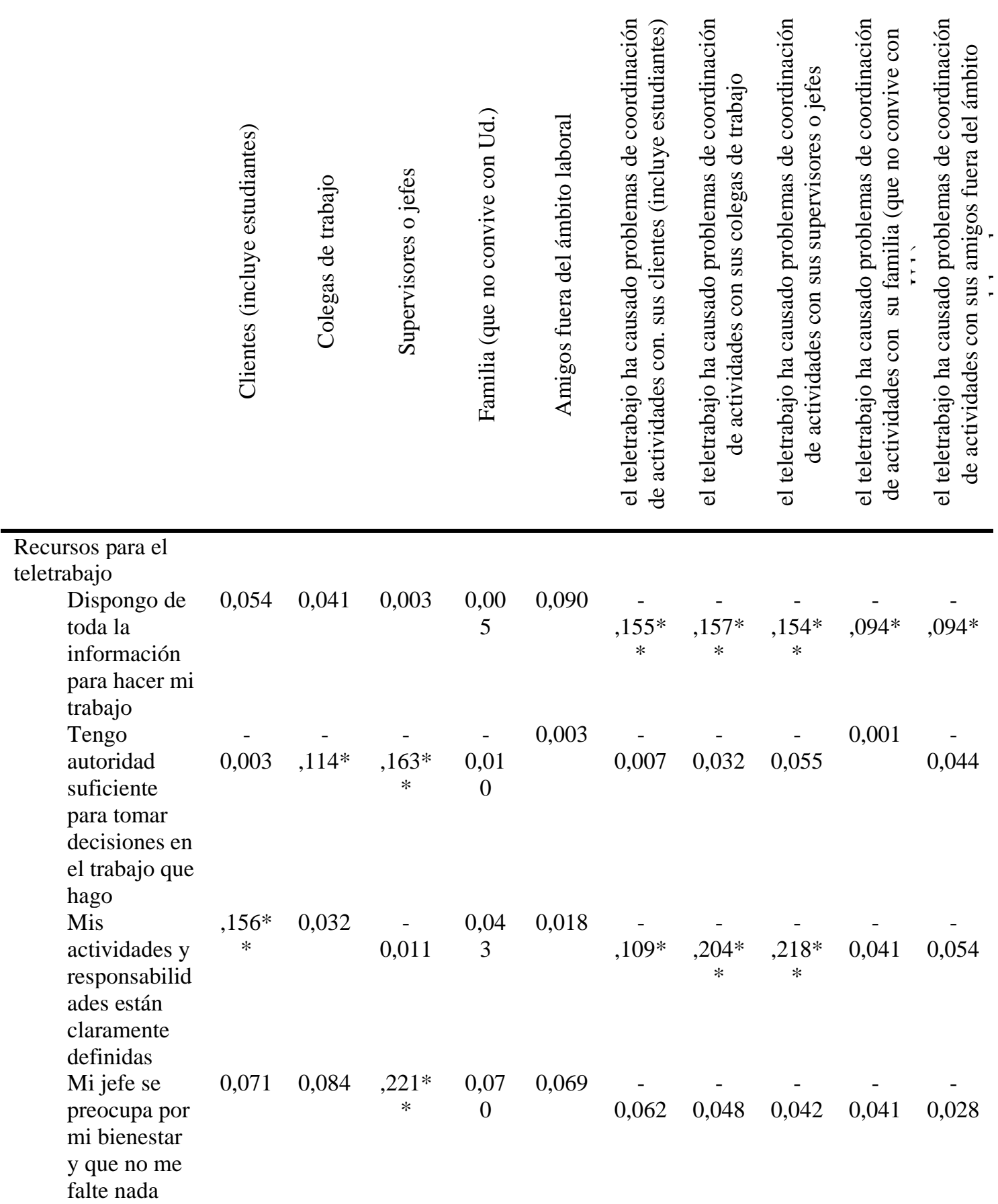
RAMOS, RAMOS-GALARZA, \& TEJERA

\begin{tabular}{|c|c|c|c|c|c|c|c|c|c|c|}
\hline $\begin{array}{l}\text { Tengo todos } \\
\text { los equipos } \\
\text { que necesito } \\
\text { para poder } \\
\text { hacer mi } \\
\text { trabajo }\end{array}$ & 0,081 & 0,033 & $\begin{array}{c}- \\
0,017\end{array}$ & $\begin{array}{c}0,01 \\
0\end{array}$ & 0,028 & $\begin{array}{c}- \\
, 136^{*} \\
*\end{array}$ & $\begin{array}{c}- \\
, 150 * \\
*\end{array}$ & $\begin{array}{c}- \\
, 188 * \\
*\end{array}$ & $\begin{array}{c}- \\
, 142 * \\
*\end{array}$ & $\begin{array}{c}- \\
0,083\end{array}$ \\
\hline $\begin{array}{l}\text { Recibo } \\
\text { retroalimenta } \\
\text { ción y tengo } \\
\text { seguimiento } \\
\text { de mi trabajo } \\
\text { d mental }\end{array}$ & 0,092 & $\begin{array}{c}129 * \\
*\end{array}$ & $\begin{array}{c}, 197 * \\
*\end{array}$ & $\begin{array}{c}0,04 \\
5\end{array}$ &, $105^{*}$ & $\begin{array}{c}- \\
0,091\end{array}$ & , $118 *$ & $\begin{array}{c}- \\
127 * \\
*\end{array}$ & $\begin{array}{c}- \\
0,059\end{array}$ & $\begin{array}{c}- \\
0,053\end{array}$ \\
\hline $\begin{array}{l}\text { Se ha } \\
\text { sentido } \\
\text { enfermo }\end{array}$ & 0,005 & 0,044 & 0,033 & $\begin{array}{c}0,05 \\
5\end{array}$ & $\stackrel{-}{0,028}$ &, $108 *$ & $\begin{array}{c}142 * \\
*\end{array}$ & $\begin{array}{c}, 139 * \\
*\end{array}$ & $\begin{array}{c}, 147 * \\
*\end{array}$ & 0,087 \\
\hline $\begin{array}{l}\text { Ha tenido } \\
\text { dolores de } \\
\text { cabeza }\end{array}$ & 0,003 & 0,061 & 0,072 & $\begin{array}{c}0,01 \\
5\end{array}$ & ${ }^{-}, 104 *$ & 0,082 &, $117 *$ &, $113^{*}$ & $\begin{array}{c}, 144^{*} \\
*\end{array}$ &, $112^{*}$ \\
\hline $\begin{array}{l}\text { Ha sentido } \\
\text { presión en la } \\
\text { cabeza }\end{array}$ & 0,004 & 0,084 &, $096 *$ & $\begin{array}{c}0,04 \\
2\end{array}$ & $\begin{array}{c}- \\
0,089\end{array}$ &, $092 *$ &, $115^{*}$ & $\begin{array}{c}145^{*} \\
*\end{array}$ & $\begin{array}{c}, 148 * \\
*\end{array}$ & 0,090 \\
\hline $\begin{array}{l}\text { Ha perdido } \\
\text { el sueño por } \\
\text { preocupacion } \\
\text { es }\end{array}$ & 0,022 & 0,032 & $\stackrel{-}{0,074}$ & $\begin{array}{c}0,02 \\
9\end{array}$ & $\stackrel{-}{0,029}$ &, $092 *$ &, $112^{*}$ & $\begin{array}{c}150 * \\
*\end{array}$ & $\begin{array}{c}, 211 * \\
*\end{array}$ & $\begin{array}{c}, 173^{*} \\
*\end{array}$ \\
\hline $\begin{array}{l}\text { Ha estado } \\
\text { con } \\
\text { problemas de } \\
\text { conciliar el } \\
\text { sueño }\end{array}$ & $\stackrel{-}{0,008}$ & 0,013 & $\stackrel{-}{0,075}$ & $\begin{array}{c}0,00 \\
7\end{array}$ & 0,005 &, $100^{*}$ & $\begin{array}{c}, 146^{*} \\
*\end{array}$ & $\begin{array}{c}, 149 * \\
*\end{array}$ & $\begin{array}{c}, 214 * \\
*\end{array}$ & $\begin{array}{c}185^{*} \\
*\end{array}$ \\
\hline $\begin{array}{l}\text { Se siente } \\
\text { constanteme } \\
\text { nte bajo } \\
\text { estrés }\end{array}$ & 0,004 & 0,036 & 0,016 & $\begin{array}{c}- \\
0,03 \\
2\end{array}$ & $\begin{array}{c}- \\
, 140 * \\
*\end{array}$ & $\begin{array}{c}149 * \\
*\end{array}$ & $\begin{array}{c}, 191 * \\
*\end{array}$ & $\begin{array}{c}178 * \\
*\end{array}$ & $\begin{array}{c}, 230 * \\
*\end{array}$ & $\begin{array}{c}158^{*} \\
*\end{array}$ \\
\hline $\begin{array}{l}\text { Ha estado } \\
\text { molesto y } \\
\text { con mal } \\
\text { temperament } \\
\text { o }\end{array}$ & $\stackrel{-}{0,003}$ & 0,003 & $\stackrel{-}{0,008}$ & $\begin{array}{c}0,05 \\
3\end{array}$ & $\stackrel{-}{0,058}$ & $\begin{array}{c}146^{*} \\
*\end{array}$ & $\begin{array}{c}, 171 * \\
*\end{array}$ &, $119 *$ & $\begin{array}{c}, 141^{*} \\
*\end{array}$ & ,099* \\
\hline $\begin{array}{l}\text { Ha estado } \\
\text { nervioso todo } \\
\text { el tiempo }\end{array}$ & $\stackrel{-}{0,046}$ & 0,037 & 0,052 & $\begin{array}{c}- \\
0,01 \\
4\end{array}$ & $\stackrel{-}{0,032}$ & 0,083 & ,097* & $\begin{array}{c}149 * \\
*\end{array}$ & $\begin{array}{c}, 200 * \\
*\end{array}$ & $\begin{array}{c}, 184^{*} \\
*\end{array}$ \\
\hline $\begin{array}{l}\text { Siente que } \\
\text { las cosas le } \\
\text { toman más } \\
\text { tiempo para } \\
\text { hacerse }\end{array}$ & $\begin{array}{c}- \\
0,002\end{array}$ & 0,049 & 0,032 & $\begin{array}{c}0,02 \\
7\end{array}$ & $\stackrel{-}{109 *}$ & $\begin{array}{c}, 199 * \\
*\end{array}$ & $\begin{array}{c}255^{*} \\
*\end{array}$ & $\begin{array}{c}, 206^{*} \\
*\end{array}$ & $\begin{array}{c}175^{*} \\
*\end{array}$ & $\begin{array}{c}171^{*} \\
*\end{array}$ \\
\hline $\begin{array}{l}\text { Se siente } \\
\text { capaz de } \\
\text { tomar buenas } \\
\text { decisiones }\end{array}$ & 0,053 & $\begin{array}{c}132 * \\
*\end{array}$ & 0,084 & $\begin{array}{c}0,05 \\
2\end{array}$ & 0,045 & ${ }^{-}$ & $\begin{array}{c}- \\
, 149 * \\
*\end{array}$ & $\begin{array}{c}- \\
, 135 * \\
*\end{array}$ & $\stackrel{-}{0,021}$ & $\begin{array}{c}- \\
0,087\end{array}$ \\
\hline $\begin{array}{l}\text { Consigue } \\
\text { disfrutar de } \\
\text { las } \\
\text { actividades } \\
\text { diarias }\end{array}$ & $\begin{array}{c}- \\
0,023\end{array}$ & $\begin{array}{c}121 * \\
*\end{array}$ & 0,056 & $\begin{array}{c}- \\
0,01 \\
0\end{array}$ & 0,041 & $\begin{array}{c}- \\
, 167 * \\
*\end{array}$ & $\begin{array}{c}- \\
\text {,213* } \\
*\end{array}$ & $\begin{array}{c}- \\
, 199 * \\
*\end{array}$ & $\begin{array}{c}- \\
{ }^{-} \\
*\end{array}$ & $\begin{array}{c}- \\
, 149 * \\
*\end{array}$ \\
\hline $\begin{array}{l}\text { Consigue } \\
\text { mantenerse } \\
\text { ocupado }\end{array}$ & 0,090 & $\begin{array}{c}163 * \\
*\end{array}$ & 0,065 & $\begin{array}{c}0,03 \\
2\end{array}$ & $\begin{array}{c}- \\
0,011\end{array}$ & - & - & $\begin{array}{c}- \\
0,060\end{array}$ & $\begin{array}{c}- \\
0,030\end{array}$ & $\begin{array}{c}- \\
0,015\end{array}$ \\
\hline
\end{tabular}




\begin{tabular}{|c|c|c|c|c|c|c|c|c|c|c|}
\hline $\begin{array}{l}\text { Se siente } \\
\text { una persona } \\
\text { con menos } \\
\text { valía }\end{array}$ & $\begin{array}{c}- \\
0,031\end{array}$ & $\stackrel{-}{-}, 098^{*}$ & $\begin{array}{c}- \\
, 096^{*}\end{array}$ & $\begin{array}{c}- \\
0,06 \\
1\end{array}$ & $\begin{array}{c}- \\
0,031\end{array}$ & 0,023 & $\begin{array}{c}- \\
0,003\end{array}$ & 0,005 & 0,072 & 0,091 \\
\hline $\begin{array}{l}\text { Siente que la } \\
\text { vida no tiene } \\
\text { sentido }\end{array}$ & $\stackrel{-}{, 103 *}$ & $\stackrel{-}{0,023}$ & $\begin{array}{c}- \\
0,012\end{array}$ & $\begin{array}{l}- \\
, 113 \\
*\end{array}$ & $\begin{array}{c}- \\
0,047\end{array}$ & 0,020 & 0,029 & 0,055 & 0,047 & 0,008 \\
\hline $\begin{array}{l}\text { Siente que } \\
\text { no consigue } \\
\text { hacer las } \\
\text { cosas por su } \\
\text { estado } \\
\text { mental }\end{array}$ & 0,004 & $0,-$ & $\begin{array}{c}- \\
0,010\end{array}$ & $\begin{array}{c}0,01 \\
7\end{array}$ & $\begin{array}{c}- \\
0,014\end{array}$ & 0,015 & 0,064 & 0,058 & 0,064 & 0,045 \\
\hline
\end{tabular}

Igualmente sucede cuando los recursos para trabajar falta, pues hay correlaciones negativas con la salud mental como se puede observar en la Tabla 7.

Tabla 6

Correlaciones entre recursos y salud mental en el teletrabajo

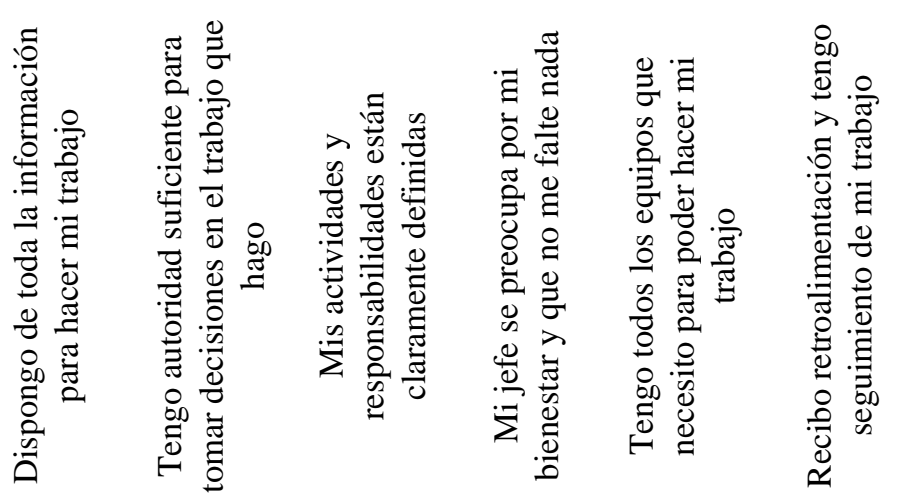

Salud mental

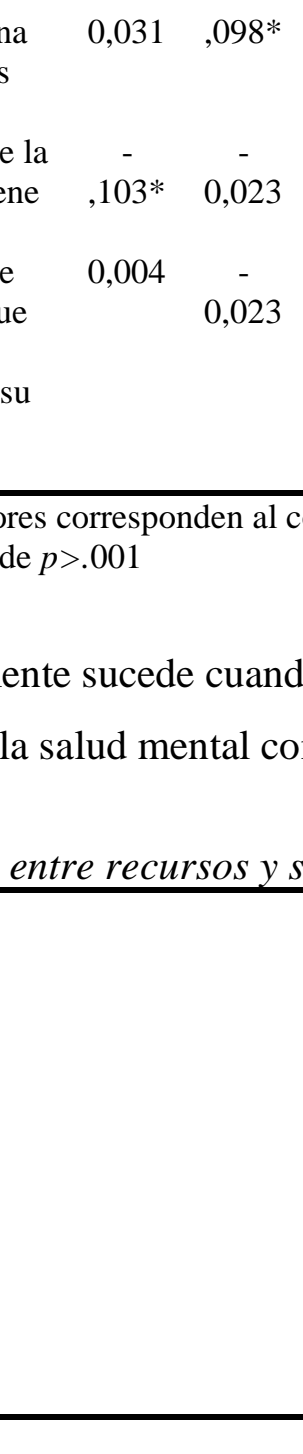

Se ha sentido enfermo

$$
-, 183 * *
$$

Ha tenido dolores de cabeza

Ha sentido presión en la cabeza

Ha perdido el sueño por preocupaciones

Ha estado con problemas de conciliar el sueño

Se siente constantemente bajo estrés

Ha estado molesto y con mal temperamento

Ha estado nervioso todo el tiempo

Siente que las cosas le toman más tiempo para hacerse

Se siente capaz de tomar buenas decisiones

Consigue disfrutar de las actividades diarias

$\begin{array}{cccccc}-, 183 * * & -, 168 * * & -, 162 * * & -, 104 * & -, 169 * * & -, 174 * * \\ -0,067 & -, 101 * & -, 127 * * & -0,054 & -, 133 * * & -, 159 * * \\ -0,073 & -, 164 * * & -, 190 * * & -0,060 & -, 160 * * & -, 128 * * \\ -, 149 * * & -, 189 * * & -, 199 * * & -, 172 * * & -, 156 * * & -, 233 * * \\ -, 129 * * & -, 151 * * & -, 181 * * & -, 183 * * & -, 171 * * & -, 249 * * \\ -, 127 * * & -, 133 * * & -, 211 * * & -, 225 * * & -, 223 * * & -, 234 * * \\ -, 137 * * & -, 127 * * & -, 227 * * & -, 165 * * & -, 143 * * & -, 235 * * \\ -0,058 & -, 127 * * & -, 125 * * & -0,055 & -, 110 * & -, 110 * \\ -, 145 * * & -, 129 * * & -, 235 * * & -, 191 * * & -, 201 * * & -, 272 * * \\ 0,066 & 0,005 & 0,047 & -0,004 & 0,018 & 0,039 \\ 0,057 & 0,007 & , 109 * & -0,013 & , 101 * & 0,021\end{array}$


RAMOS, RAMOS-GALARZA, \& TEJERA

$\begin{array}{lllllll}\begin{array}{l}\text { Consigue mantenerse } \\ \text { ocupado }\end{array} & 0,004 & -0,039 & -0,002 & -, 110^{*} & -0,052 & -0,025 \\ \begin{array}{l}\text { Se siente una persona con } \\ \text { menos valía }\end{array} & -0,029 & -0,045 & -0,055 & -, 127 * * & -0,038 & -, 104^{*} \\ \begin{array}{l}\text { Siente que la vida no tiene } \\ \text { sentido }\end{array} & -0,087 & -0,081 & -, 167^{* *} & -, 112^{*} & -, 146^{* *} & -, 108^{*} \\ \begin{array}{l}\text { Siente que no consigue } \\ \text { hacer las cosas por su estado } \\ \text { mental }\end{array} & -0,069 & -0,045 & -, 136^{* *} & -, 105^{*} & -, 098^{*} & -, 149 * * \\ \quad & & & & & \\ \quad \begin{array}{l}\text { Los valores corresponden al coeficiente de correlación de Pearson. El *indica valores de } p<.05 \mathrm{y} \\ \text { ica valores de } p>.001\end{array}\end{array}$

\section{Discusiones}

De acuerdo con los resultados presentados, podemos llegar a algunas afirmaciones que pasaremos a discutir a continuación:

\section{La productividad se ha visto impactada por las condiciones de teletrabajo}

Estudios realizados previamente, apoyan la idea que el teletrabajo contribuye de forma positiva a la percepción de la productividad. De acuerdo con Westfall (1997), las personas que se encuentran realizando teletrabajo tienen un aumento de su productividad en un $10 \%$ en comparación con las personas que realizan un tipo de trabajo estándar. El $41 \%$ de las personas que respondieron el cuestionario de la presente investigación indicaron que su productividad se había mantenido estable, el 33\% indicaron que había disminuido y el $26 \%$ indicó que su productividad había aumentado. Autores como Ruth y Chaudhry (2008) confirman estos resultados, una vez que demuestran que, por causa del teletrabajo, se puede mejorar la motivación de las personas y aumentar los niveles de retención, sin embargo, en sus investigaciones encontraron que los niveles de productividad como tal permanecieron los mismos. Adicionalmente, Neufeld y Fang (2005) indicaron que la productividad aumenta cuando existen condiciones que la favorecen. Por tanto, no sería el teletrabajo en sí, sino las condiciones del teletrabajo las que favorecerían el aumento o no de la productividad, lo cuál también se ha verificado en la presente investigación (Attaran et al., 2019; Beauregard et al., 2019; Neufeld \& Fang, 2005).

\section{Las competencias que más influyen en los elementos del teletrabajo son la automotivación y la capacidad de organización}

La automotivación es una de las competencias que se ha identificado como esenciales para el éxito de la persona que está en condiciones de teletrabajo. De acuerdo 
con Hamilton (2002), la automotivación en el teletrabajo es la capacidad de las personas para establecer ellas mismas sus rutinas de trabajo y determinar plazos de entrega de tareas, sin depender de un jefe que tenga que controlar las actividades que realiza. De este modo, las responsabilidades por realizar las tareas recaen en la propia persona y los jefes son capaces de promover esta competencia para el éxito de sus subordinados (Peters et al., 2016; Snyder, 2012; Standen et al., 1999).

Por su parte, la organización del tiempo y del espacio ha sido otra de las competencias que también se han relacionado con el éxito durante las actividades de teletrabajo. Según Lewis (1994), la autodisciplina, que se refleja en la capacidad de organización y de generar una estructura diaria de trabajo, así como un espacio físico para poder realizas las actividades laborales; permiten que las personas establezcan rutinas y definan las fronteras entre lo que es el espacio laboral y el espacio doméstico, para conseguir un equilibrio entre ambos (Gądecki et al., 2018; Lewis, 1994). En caso de que el teletrabajador no posea esta competencia, se ha verificado una disminución de la satisfacción laboral y el rendimiento (Smith et al., 2018). De este modo, nuestros resultados confirman resultados previamente encontrados por otros autores consultados.

\section{Cuando no hay recursos ni condiciones para el teletrabajo hay una afectación de la salud mental}

En relación a la salud mental, estudios confirman que el teletrabajo ha traído estados positivos de satisfacción general pero, al mismo tiempo, es fuente de un aumento del estrés y otros estados negativos como la depresión (Beauregard et al., 2019; Tavares, 2017). De acuerdo con (Tavares, 2017), el impacto en la salud mental como consecuencia del teletrabajo aparece cuando se extiende la jornada laboral. Otros aspectos que también afectan la salud mental se relacionan con el aislamiento social y las capacidades de tener control en relación a las actividades que se realizan durante el teletrabajo (Hager, 2018). De esta forma, cuando el teletrabajo representa un problema debido a la imposibilidad de ajustar responsabilidades y relaciones, se dan problemas de salud, cuya afectación tiene una connotación tanto psicológica como general en la calidad de vida del teletrabajador (Hilbrecht et al., 2008).

\section{Conclusiones}


Los resultados presentados relevan la realidad de las personas que se encuentran en teletrabajo debido al aislamiento social debido a la enfermedad del COVID-19. En este sentido, el teletrabajo se ha verificado como positivo en la productividad, siempre y cuando se cuenten con los recursos necesarios para trabajar y las condiciones relacionadas con la salud mental sean igualmente favorables. Dentro de estos recursos se encuentran las competencias como recursos personales, pero también hace referencia a las características del trabajo, a las condiciones en que se está trabajando desde el hogar, a los apoyos recibidos, etc. El desarrollo de la automotivación y de la autodisciplina o la organización, como competencias, han demostrado no solamente tener un efecto positivo en la productividad, sino en la sensación de bienestar y satisfacción producida por el teletrabajo. Al mismo tiempo, cuando las personas perciben que tienen todos los recursos para trabajar, así como los espacios físicos y las no interrupciones en su proceso, resulta más fácil determinar las fronteras del trabajo y el hogar, y potencia la estructuración de las actividades y la salud mental.

Este estudio permite estructurar acciones a nivel organizacional para dar apoyo a las personas que se encuentran en teletrabajo pues, al facilitar las condiciones para el mismo desde las decisiones de los líderes y las distintas estructuras organizacionales, contribuye a que el trabajador que se encuentra en aislamiento, con ansiedades dadas por la incertidumbre y el miedo al contagio, pueda llevar adelante su trabajo a distancia. Se debe destacar la importancia de que este tipo de "nueva realidad" como se le da denominado no es un elemento pasajero y que las medidas que se tomen relacionada con el bienestar físico y mental de los trabajadores serán necesarias no solamente mientras dure la pandemia, sino que pueden ser adoptadas como parte del proceso de transformación organizacional de las empresas que reorienten a sus colaboradores hacia actividades de teletrabajo de forma más permanente, incluso si es que adoptan modalidades mixtas donde se combinen estrategias de trabajo desde el hogar y de forma presencial.

\section{Limitaciones}

Uno de los aspectos de la investigación que se puede identificar como limitación está en el acceso a las muestras de una mayor cantidad de regiones para poder realizar comparaciones. En el caso de Ecuador, existe una diferencia entre regiones como Guayaquil, donde se dieron los primeros brotes de la enfermedad, y Quito, donde la enfermedad llegó posteriormente. Cada región cuenta con características especificas que 
podrían hacer que también desde la lógica de la cultura organizacional los comportamientos también sean diferentes. Otra limitación identificada está dada por el período del levantamiento de los datos. Es recomendable volver a levantar los datos pasado un tiempo para verificar si los elementos que afectan la percepción de productividad se mantienen a lo largo del tiempo.

\section{Pistas para futuras investigaciones}

Esta investigación es un primer estudio sobre el tema del teletrabajo en las condiciones provocadas por la pandemia del COVID-19, por tanto, resulta interesante hacer un estudio longitudinal donde se puedan evaluar las mismas características pasado un tiempo de las personas haber dado inicio al aislamiento social. Igualmente sería importante realizar el estudio una vez que las personas continúen en situación de teletrabajo una vez terminada la pandemia del COVID-19 para realizar comparaciones. Los estudios transculturales, donde se comparan realidades en diferentes contextos, también podrían ser una alternativa de investigación. Así se podrían entender cómo las personas en distintas regiones han vivido este proceso.. 


\section{Referencias}

Arce-Villalobos, L. R., \& Rodriguez-Morales, A. J. (2020). Enfermedad por Coronavirus 2019 ( COVID-19 ) en América Latina : Papel de la atención primaria en la Preparación y respuesta. Atención Primaria, 2019(April). https://doi.org/10.13140/RG.2.2.11637.52966

Atkinson, R., \& Flint, J. (2001). Accessing Hidden and Hard-to-Reach Populations: Snowball Research Strategies. Social Research Update, 33(1), 1-4.

Attaran, M., Attaran, S., \& Kirkland, D. (2019). The need for digital workplace: Increasing workforce productivity in the information age. International Journal of Enterprise Information Systems, 15(1), 1-23. https://doi.org/10.4018/IJEIS.2019010101

Beauregard, T. A., Basile, K. A., \& Canonico, E. (2019). Telework: Outcomes and Facilitators for Employees. In The Cambridge Handbook of Technology and Employee Behavior (Issue February). Cambridge University Press. https://doi.org/10.1017/9781108649636.020

Crawford, J. O., MacCalman, L., \& Jackson, C. A. (2011). The health and well-being of remote and mobile workers. Occupational Medicine, 61(6), 385-394. https://doi.org/10.1093/occmed/kqr071

Dirección de Relaciones Públicas. (2020). Secretaria General de Comunicación de la Presidencia. Se Registra El Primer Caso de Coronavirus En Ecuador. https://www.comunicacion.gob.ec/se-registra-el-primer-caso-de-coronavirusen-ecuador/

Felstead, A., \& Henseke, G. (2017). Assessing the growth of remote working and its consequences for effort, well-being and work-life balance. New Technology, Work and Employment, 32(3), 195-212. https://doi.org/10.1111/ntwe.12097

Gądecki, J., Jewdokimow, M., \& Żadkowska, M. (2018). New technologies and family life in the context of work at home. The strategies of work-life balance. Studia Humanistyczne AGH, 17(4), 77. https://doi.org/10.7494/human.2018.17.4.77

Hager, F. W. (2018). Links Between Telecommuting, Social Support and Mental Well-Being Among Teleworkers - a Literature Review. International Journal of Business and Management, VI(2), 36-58. https://doi.org/10.20472/bm.2018.6.2.003

Hamilton, E. (2002). Bringing Work Home: Advantages and Challenges of Telecommuting (pp. 1-32). http://www.bc.edu/content/dam/files/centers/cwf/research/publications/pdf/B CCWF Telecommuting Paper.pdf

Hilbrecht, M., Shaw, S. M., Johnson, L. C., \& Andrey, J. (2008). 'I'm Home for the Kids': Contradictory Implications for Work-Life Balance of Teleworking Mothers. Gender Work and Organization, 15(5).

INEC. (2020). Instituto Nacional de Estadística y Censos. Población y Demografía. https://www.ecuadorencifras.gob.ec/censo-de-poblacion-y-vivienda/

Israel, G. D. (1992). Determining Sample Size. University of Florida, IFAS Extension, PEOD6(April 2009), 1-5. https://doi.org/10.4039/Ent85108-3

Kossek, E. E., Lautsch, B. A., \& Eaton, S. C. (2009). “Good teleworking”: Under what conditions does teleworking enhance employees' well-being? In Technology and Psychological Well-being (Issue January). https://doi.org/10.1017/CBO9780511635373.007 
Lewis, A. (1994). The experience of teleworking: An annotated review. The International Journal of Human Resource Management, 5(1), 193-223. https://doi.org/10.1080/09585199400000010

Ministerio del Trabajo. (2019). Directrices para la prevención y protección de los trabajadores y servidores públicos frente al coronavirus (covid-19) dentro de los espacios laborales. In Journal of Chemical Information and Modeling (Vol. 53, Issue 9, pp. 1689-1699). https://doi.org/10.1017/CBO9781107415324.004

Ministerio del Trabajo. (2020). ACUERDO-MDT-2020-076-TELETRABAJO. Directrices para la aplicación del teletrabajo emergente durante la declaratoria de emergencia sanitaria. Ministerio del Trabajo.

Neufeld, D. J., \& Fang, Y. (2005). Individual, social and situational determinants of telecommuter productivity. Information and Management, 42(7), 1037-1049. https://doi.org/10.1016/j.im.2004.12.001

OIT. (2020a). Las normas de la OIT y el COVID-19 (Vol. 19). OIT.

OIT. (2020b). Observatorio de la OIT - segunda edición : El COVID-19 y el mundo del trabajo Estimaciones actualizadas y análisis. OIT.

Peters, P., Ligthart, P. E. M., Bardoel, A., \& Poutsma, E. (2016). 'Fit' for telework'? Cross-cultural variance and task-control explanations in organizations' formal telework practices. International Journal of Human Resource Management, 27(21), 2582-2603. https://doi.org/10.1080/09585192.2016.1232294

PwC Ecuador. (2020). Emergencia Sanitaria COVID-19 (Vol. 11, Issue 11, p. 2020). PwC Asesores Empresariales Cia. Ltda.

Ruth, S., \& Chaudhry, I. (2008). Telework: A productivity paradox? IEEE Internet Computing, 12(6), 87-90. https://doi.org/10.1109/MIC.2008.132

Smith, S. A., Patmos, A., \& Pitts, M. J. (2018). Communication and teleworking: A study of communication channel satisfaction, personality, and job satisfaction for teleworking employees. International Journal of Business Communication, 55(1), 44-68. https://doi.org/10.1177/2329488415589101

Snyder, K. (2012). Enhancing Telework: A Guide to Virtual Leadership. Public Manager, 41, 11-14. http://libezproxy.open.ac.uk/login?url=http://search.ebscohost.com/login.aspx ?direct=true $\& \mathrm{db}=\mathrm{a} 9 \mathrm{~h} \& \mathrm{AN}=73181784 \&$ site=eds-live \&scope $=$ site

Standen, P., Daniels, K., \& Lamond, D. (1999). The home as a workplace: workfamily interaction and psychological well-being in telework. Journal of Occupational Health Psychology, 4(4), 368-381. https://doi.org/10.1037/1076-8998.4.4.368

STATISTA. (2020). STATISTA. Number of Confirmed Cases of Novel Coronavirus (COVID-19) in Latin America and the Caribbean as of April 14, 2020, by Country. https://www.statista.com/statistics/1101643/latin-americacaribbean-coronavirus-cases/

Tavares, A. I. (2017). Telework and health effects review. International Journal of Healthcare, 3(2), 30. https://doi.org/10.5430/ijh.v3n2p30

Westfall, R. D. (1997). Does telecommuting really increase productivity? Fifteen rival hypotheses. Proceedings of the AIS Americas Conference, 405-407. 